\title{
Regulatory Contracts and Cost Efficiency: \\ Stochastic Frontier Evidence from the Italian Local Public Transport
}

[Premio Young Economist EARIE 2002]

Massimiliano PIACENZA

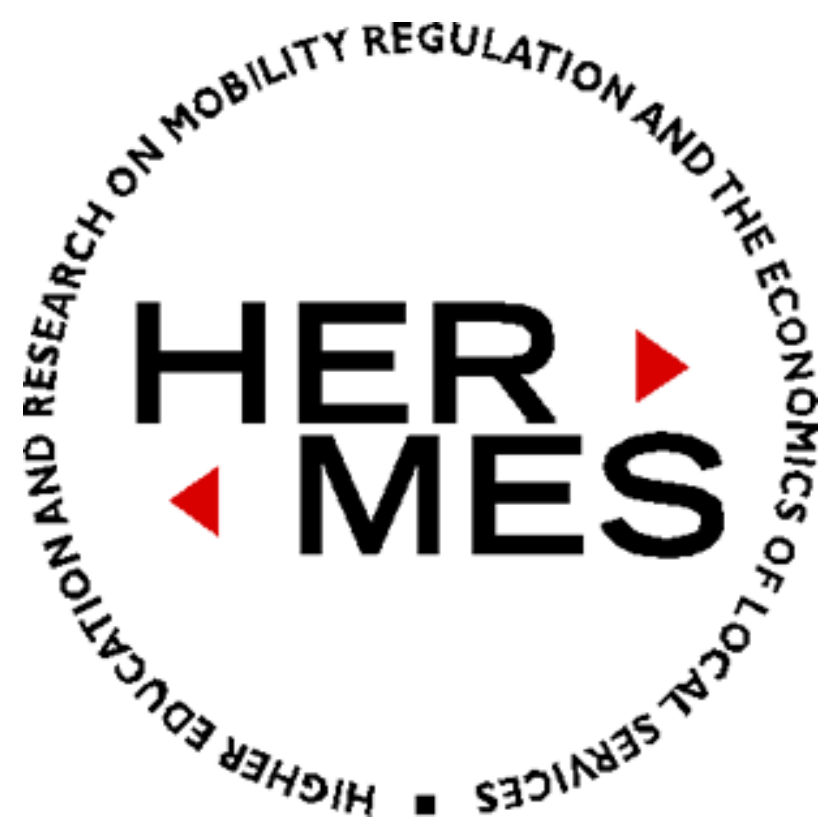

Working Paper 2, 2002 


\section{(C) Hermes}

Real Collegio Carlo Alberto

Via Real Collegio, 30

10024 Moncalieri (To)

0116402713 - 6423970

info@hermesricerche.it

http://www.hermesricerche.it

I diritti di riproduzione, di memorizzazione e di adattamento totale o parziale con qualsiasi mezzo (compresi microfilm e copie fotostatiche) sono riservati.

\section{PRESIDENTE}

Giovanni Fraquelli

\section{SEGRETARIO}

Cristina Piai

\section{SEGRETERIA OPERATIVA}

Giovanni Biava

\section{COMITATO DIRETTIVO}

Giovanni Fraquelli (Presidente)

Cristina Piai (Segretario)

Guido Del Mese (ASSTRA)

Carla Ferrari (Compagnia di San Paolo)

Giancarlo Guiati (ATM S.p.A.)

Mario Rey (Università di Torino)

\section{COMITATO SCIENTIFICO}

Tiziano Treu (Presidente, Università "Cattolica del Sacro Cuore" di Milano e Senato della Repubblica)

Giuseppe Caia (Università di Bologna)

Roberto Cavallo Perin (Università di Torino)

Carlo Corona (CTM S.p.A.)

Graziella Fornengo (Università di Torino)

Giovanni Fraquelli (Università del Piemonte Orientale "A. Avogadro")

Carlo Emanuele Gallo (Università di Torino)

Giovanni Guerra (Politecnico di Torino)

Marc Ivaldi (IDEI, Universitè des Sciences Sociales de Toulouse)

Carla Marchese (Università del Piemonte Orientale "A. Avogadro")

Luigi Prosperetti (Università di Milano "Bicocca")

Alberto Romano (Università di Roma "La Sapienza")

Paolo Tesauro (Università di Napoli "Federico" II) 


\title{
REGULATORY CONTRACTS AND COST EFFICIENCY: STOCHASTIC FRONTIER EVIDENCE FROM The Italian Local Public Transport*
}

\author{
MASSIMILIANO PIACENZA \\ (Ceris-CNR, HERMES)*
}

November 2002

\begin{abstract}
The main objective of this paper is to investigate the way subsidization mechanisms affect the cost efficiency of public transit systems, taking into account the role played by the environmental characteristics of each network. To this end, a cost frontier model is estimated for a seven-year (1993-1999) panel of 45 Italian transit companies run under two different regulatory schemes (cost-plus or fixed-price), using the methodology proposed by Battese and Coelli (1995). The main evidence is that, given network characteristics, transit operators with high-powered incentive contracts (fixed-price subsidies) exhibit lower distortions from minimum costs. Environmental conditions (network speed levels) also have a significant impact on inefficiency differentials. Overall, these results highlight a scope for transport policy to increase X-efficiency. Furthermore, they confirm the importance of incentive theory and modern regulatory economics for the production analysis of regulated utilities.
\end{abstract}

Keywords: local public transport, subsidies regulation, incentives, cost efficiency, stochastic frontier.

JEL Code: C13, C24, L51, L92, R41.

\footnotetext{
* This study has been carried out within the Ceris-CNR / HERMES project "I trasporti locali: dal sussidio all'incentivazione e all'efficienza". A previous version of the paper was presented at the Brown Bag seminar in economics Efficienza e regolamentazione delle compagnie italiane di trasporto pubblico locale, Università della Svizzera Italiana, Lugano, Switzerland, November 28, 2001, the HERMES $1^{\text {st }}$ Conference Regolamentazione $e$ incentivi nel trasporto pubblico locale: esperienze a confronto e proposte per il caso italiano, Moncalieri (Torino), Italy, December 3, 2001, the European Public Choice Society (EPCS) 2002 Annual Meeting, Belgirate, Italy, April 4-7, 2002, and the $29^{\text {th }}$ Annual Conference of the European Association for Research in Industrial Economics (EARIE), Madrid, Spain, September 5-8, 2002. I would like to thank all those who took part in these conferences, in particular Philippe Gagnepain, Marc Ivaldi, and Karl Robertsen, for their useful discussions. I am also grateful to Luigi Benfratello, Massimo Filippini, Giovanni Fraquelli, Carla Marchese, Diego Piacentino, Davide Vannoni and Luigi Ventura for their helpful comments on earlier versions of the paper. I acknowledge the financial support of HERMES and the assistance of ASSTRA in collecting data.
} * Mailing address: Institute for Economic Research on Firms and Growth (Ceris-CNR), Via Avogadro 8, 10121
Turin, Italy. Phone: +39-(0)11-5601241. Fax: +39-(0)11-5626058. E-mail: m.piacenza@ceris.to.cnr.it.

This is one of the prizewinning essays in the Young Economists' Award Competition of the $29^{\text {th }}$ Annual Conference of the EARIE, University Carlos III, Madrid, Spain, September 5-8, 2002. 


\section{Introduction}

A common feature of the regulatory framework of local public transport (LPT) in most countries is the provision for transfers from a regulation authority to the transit company. Since the latter generally face universal service obligations, commercial revenues are not high enough to cover operating costs. The payment of a subsidy is then required to ensure the balance of the budget. In most European countries, including Italy, this practice has led to a growing waste of public resources to cope with the consistent build up of deficits and the financial crisis faced by LPT firms. A better understanding of the sources of cost inefficiency in this industry may then be useful for reassessing traditional state intervention and designing new regulatory policies, in particular, with regard to contractual arrangements ruling the grant of subsidies.

Few studies have explicitly analyzed the role of different subsidization mechanisms in explaining inefficiency differentials among LPT operators. ${ }^{1}$ The core of the present paper is to put forward information on the X-efficiency (Leibenstein, 1966) of public transit systems in Italy, investigating the way regulatory contracts affect the distortions from the best-practice behavior of cost minimization. Since environmental characteristics of each network are likely to play an important role when dealing with cross section data to measure cost performance of transport companies, an attempt is made in the analysis to control for these effects using observable network variables. The results of this research are relevant for several reasons. First, they make a contribution to the debate as to whether the predictions from incentive theory (Laffont and Tirole, 1993) help explain differences in productive efficiency among firms. Moreover, providing rigorous empirical evidence on the impact of different mechanisms for granting subsidies, our results have immediate policy implications for the ongoing regulatory reform in the Italian LPT sector, as will be explained in more detail below.

The analysis is based on a seven-year (1993-1999) unbalanced panel data of 45 Italian municipal companies managed under two regulatory schemes (i.e. cost-plus or fixed-price) and facing different levels of network commercial speed. The observed time period is particularly informative, as it encompasses both the years before and after the start-up of the reform. A stochastic frontier cost function is estimated using the methodology proposed by Battese and Coelli (1995). This panel model assumes the inefficiency terms to be a function of a set of explanatory variables including both firm-specific and time effects. In particular, the focus of the present study is on the way regulatory contracts, network characteristics, and their interaction affect $\mathrm{X}$-inefficiency.

\footnotetext{
${ }^{1}$ These include the contributions by Kerstens (1996) and Gagnepain \& Ivaldi (2002a,b) for the French urban transit industry and the ones by Dalen \& Gomez-Lobo $(1996,1997,2001)$ for Norway.
} 
The rest of the paper is organized as follows. Section 2 briefly summarizes the regulation of the Italian LPT industry in the last decade, focusing on the subsidization schemes and the related incentive mechanisms. In Section 3, we develop the econometric model. Section 3.1, specifies the stochastic frontier cost function, while Section 3.2 deals with the modeling of cost inefficiency effects. The database is described in Section 4. Section 5 comments on the empirical results, discussing both the technology properties (Section 5.1) and the evidence on $\mathrm{X}$-inefficiency (Section 5.2). Section 6 summarizes the major findings and provides some policy indications.

\section{Subsidies regulation and incentives to efficiency: the Italian framework}

During the first half of the nineties, many efforts were made whit the aim of redressing the ruinous financial imbalance faced by the Italian LPT sector. Nevertheless, these interventions were only stopgap measures, that turned out to be inadequate to achieve the general goal of a structural readjustment of industry accounts. Only in the last seven years have radical regulatory changes been introduced in order to obtain the required improvements in terms of efficiency and effectiveness of the service and reduce the waste of public funds spent on collective transports. ${ }^{2}$ In 1995, Law 549 brought about the abolition of the old system of redressing deficits of LPT firms through resources drawn on the National Transport Fund, a central government grant system created specifically for this purpose. The opportunity cost of public funds was thereby transferred to the Regions, who are nowadays in charge of the programming of services. Subsequently the Reform has been implemented by the Decreti Legislativi 422/1997 and 400/1999.

An important innovation that the legislator tried to introduce in the organization of local public transport is the increase of the financial responsibility of all the subjects operating in the sector, i.e., local authorities and LPT firms. The purpose is to better select which public service deserves to receive subsidies ${ }^{3}$ and to stimulate the recovery of productive efficiency by transportation companies. Here it becomes necessary to eliminate the transfers from the central government and replace them with forms of taxation at regional level, in order to make binding any measures for an efficient use of public resources for local authorities. In parallel, the reform dictates that the relations between the regulatory subject and the transit service provider are governed through the so-called service contract, a formal agreement which defines the rules that the LPT company must obey as well as the reimbursement and risk sharing scheme between the regulator and the operator.

After the enactment of Law 549, subsidization practices began to develop differently in Italy. Before 1996, all LPT systems were run under cost-plus regimes, characterized by the

\footnotetext{
${ }^{2}$ In 1995 about $71 \%$ of operating costs for the Italian bus-line companies came from public subsidies.

3 Decreto Legislativo 422/1997 calls these categories "minimum services". In practice, the definition of minimum service should correspond to the level of service that a community wants to make universally and actually affordable to each of its member, normally at non-market special tariff conditions.
} 
full recovery of budget losses by local authorities. ${ }^{4}$ According to this scheme, known in the regulatory practice as management contract (European Commission, 1998), the operator does not bear any risks on costs (industrial risk) and revenue (commercial risk). Thus, in the light of the new theory of regulation (Laffont and Tirole, 1993), the operator, as it is not residual claimant for effort, has no incentives to produce efficiently,. Since 1996, some municipalities have introduced alternative reimbursement mechanisms that, even if not yet formalized within a proper service contract, have virtually overcome the ex-post balancing of accounts: the gross cost schemes, under which the industrial risk is entirely borne by the firm while the commercial risk is borne by the local authority, and the net cost schemes, that provide for the assumption of both types of risk by the operator. These two types of contractual arrangements are traceable to what the theory of incentives in regulation calls fixed-price schemes. In both cases, the transfer from the local authority is defined ex-ante, on the basis of expected operating costs (gross cost approach) or expected operating deficits (net cost approach), and realized costs/deficits that deviate from the fixed criteria will not influence the level of subsidies. Thus, compared to companies under the traditional cost-plus regime, the companies subjected to fixed-price mechanisms are assumed to face high-powered incentives towards a cost minimizing behavior. ${ }^{5}$

It is worthwhile to underline that both cost-plus and fixed-price schemes are not optimal rules in the sense specified by the new theory of regulation. According to this approach, because of the presence of informational constraints, optimal mechanisms must solve the trade-off between the efficiency incentives typical of fixed-price schemes and the rent extracting properties of a cost-plus regulation. ${ }^{6}$ The complex problem of designing an optimal contract is beyond the scope of our study, ${ }^{7}$ since only fixed-price or cost-plus schemes are carried out at the present time in the Italian LPT industry. Given the above discussion on the two regulatory mechanisms, the present paper is aimed at investigating whether transit companies run under fixed-price regimes are more cost efficient due to the fact that they face stronger incentives to increase managerial effort. If this is so, then we may conclude that incentive theory and modern regulatory economics are necessary components in the production analysis of regulated utilities. On the policy side, this investigation allows us to assess whether the subsidization schemes recently introduced in Italy are suitable in order to recover efficiency, which is one of the goals pursued by the legislative reform.

\footnotetext{
${ }^{4}$ Bolzano ACT-VVB is an exception, as it has already been subjected to a standard-cost regime from 1989 .

${ }^{5}$ Actually, with the second-type of fixed-price scheme, the so-called net cost contract, the regulated company is responsible for both insufficient revenues and cost overruns. Therefore, it has an incentive to increase traffic proceeds besides reducing operating costs, for instance by raising the quality of the service or controlling more severely the tariff evasion. However, since the focus of this study is on cost efficiency of the supply, we will not deal with issues concerning informational asymmetries between regulator and LPT operator on the demand side and related incentive problems.

${ }^{6}$ See Laffont and Tirole (1993) for a complete description of this problem.

${ }^{7}$ Regarding this regard, see Wunsch (1994), Dalen and Gomez-Lobo $(1996,1997)$ and Gagnepain and Ivaldi (2002b).
} 


\section{The econometric model}

The frontier concept arises in the econometric practice when one considers that theoretical production and cost functions represent the maximum and minimum values, respectively, of an optimization problem. In this sense the notion of cost function may be interpreted as a frontier relationship, i.e., a benchmark behavior, because it is impossible for a firm to achieve costs lower than the minimum requirement, whereas higher levels are often observed in the real world, which reveal the presence of $X$-inefficiency in the production process.

In the case of unbalanced panel data the general stochastic frontier specification for a variable cost function can be written as:

$$
\begin{aligned}
& V C_{f t}=V C\left(Y_{f t}, P_{f t}, Z_{f t}, \tau_{f t} ; \beta\right) \exp \left\{\psi_{f t}\right\}, \\
& \text { with } \psi_{f t}=v_{f t}+u_{f t},
\end{aligned}
$$

where $V C$ denotes the variable cost, $Y$ represents a vector of output, $P$ is an $m \times 1$ vector of prices of variable factors, $Z$ is an $n \times 1$ vector of variables including quasi-fixed inputs and network characteristics, $\tau$ indicates the year of the observation involved, and $\beta$ is a $k \times 1$ vector of technology parameters to be estimated. For all variables the subscript $f$ indexes firm $(f=1, \ldots, F)$, and $t$ indexes observation $\left(t=1, \ldots, T_{f}\right)$. The $f$ subscript on $T$ is used to indicate the unbalanced nature of the panel. For all $f 1 \leq T_{f} \leq T$, with $T$ denoting the maximum number of observations available for a firm. ${ }^{8}$

As usual in frontier literature, the error term $\psi_{f t}$ is decomposed into two components: $(i)$ the white noise component, $v_{f t}$, which capture the effects of all exogenous shocks to the production process and (ii) the inefficiency term, $u_{f t}$, representing firm- and time-specific cost inefficiency. The statistical noise term, $v_{f t}$, makes the frontier cost function $V C($.) stochastic and can take both positive and negative values, according to whether the exogenous shocks have unfavorable or favorable effects on cost. The non-negative error component, $u_{f t}$, on the other hand, indicates the amount by which the logarithm of cost of the $f^{\text {th }}$ firm at the $t^{\text {th }}$ observation exceeds the logarithm of stochastic frontier, $\ln V C()+.v_{f t}$, due to $\mathrm{X}$-inefficiency. When $u_{f t}=0$ for a particular firm, $f$, at observation $t$, the cost frontier is attained.

\subsection{Specification of the stochastic frontier cost function}

In order to analyze the productive structure of the Italian LPT industry we chose a variable operating cost model. The fixed assets investments in this sector are strictly related to government financing programs, so it is not proper to suppose that companies exhibit a costminimizing behavior with respect to capital too. Therefore, as Windle (1988), Levaggi (1994) and Fabbri (1998) suggest, the rolling stock should be considered as a fixed factor in the short-run. The model includes: a scalar output $(Y)$; the price of three variable factors, i.e.

\footnotetext{
${ }^{8}$ Although it is assumed that there are $T$ time periods for which observations are available for at least one of the $F$ firms involved, it is not necessary that all the firms are observed for all $T$ periods in an unbalanced panel data specification of the econometric model.
} 
labor $(L)$, fuel $(F)$, materials and services $(M S)$; a quasi-fixed input $(K)$; three network variables, i.e. the average commercial speed $(S P)$, a dummy for intercity companies (DINTC), a dummy for "mixed" operators, which supply in combination urban and intercity public transport (DMIX); a time trend variable $(\tau)$.

We use a composite measure of the output to reflect the global productive structure of firms. It is well-known in transportation literature that the output definition is a much debated issue, since it can lead to different results, for example in terms of scale economies. The output indicator is computed by multiplying the transit firm's fleet size, measured in terms of total places offered, ${ }^{9}$ and the total traveled kilometers. We wish to point out some remarks about this kind of output. If we consider the operative context of the LPT industry, a firm must supply the service on a certain number of lines, offering a certain number of places and trips on this network. Our definition of output allows us to take into account the length of the network, the frequency of the service and the size of the fleet. Furthermore, this measure is particularly suitable to our specific firm sample, which includes both urban and intercity services. As it was not possible to separate urban activity from intercity activity, we defined an aggregate output and aimed to weigh their specific characteristics. ${ }^{10}$

The capital stock plays the role of quasi-fixed input in our variable cost model. It is represented by the number of vehicles owned by LPT companies weighted by the average fleet age. We calculated the indicator as follows: $K_{f t}=$ (number of vehicles in the rolling stock). $\left(\right.$ age $_{s} /$ age $\left._{f t}\right)$, where age $e_{s}$ is the average fleet age in the whole analyzed sample, while $a g e_{f t}$ is the average fleet age of firm $f$ at the observation $t$. To some extent, this measure allows us to control for wear differences of rolling stocks and consequent effects on operating costs, especially with regards to maintenance expenses which are typically linked to the age of vehicles.

Prices of variable factors were computed using information from the balance-sheet statistics. The labor price $\left(P_{L}\right)$ was obtained by dividing total labor costs by the average annual number of service workers (drivers, maintenance workers and administrative staff). The average price of fuel $\left(P_{F}\right)$ was obtained by dividing fuel costs by the annual number of liters consumed. ${ }^{11}$ Expenses for materials and services represent a residual cost category. It has been divided by the annual seat-kilometers offered to obtain an average price for this input $\left(P_{M S}\right){ }^{12}$ Indeed, it is reasonable to assume that this kind of expense strictly depends on the actual exploitation of the network.

\footnotetext{
${ }^{9}$ The total places offered were calculated by multiplying the number of vehicles owned by each unit and their average load capacity.

${ }^{10}$ Generally speaking, the intercity firms can perform a higher number of kilometers than the urban units, covering a larger network, but the operative context is very different (a lower number of passengers, longer trips, different traffic conditions). On the other hand, a urban company reasonably offers a higher number of places (buses are larger and also their number is higher, because there is a more intensive demand to satisfy).

${ }^{11}$ For a few firms which utilize tramways, trolley-lines or railways and consume electricity, kilowatt-hours were transformed in equivalent-liters.

${ }^{12}$ Seat-kilometers are the multiplication of traveled kilometers by the average load capacity of vehicles.
} 
In addition to the standard variables of a proper cost function, we included in the model the average commercial speed of LPT vehicles $(S P)$, already considered in some works on the industry (for instance, Windle, 1988; Levaggi, 1994; Wunsch, 1996; Gagnepain, 1998). The specificity of the territorial area where the service is provided makes it difficult to compare the cost performance of different firms. Indeed, the traffic conditions and the geographical characteristics are peculiar to each network. To some extent, the average commercial speed should reflect differences in these environmental factors. Incorporating the variable into the cost frontier, costs are expected to lower with increasing network speed. Moreover, since our sample embraces LPT companies providing urban, intercity, or both types of service, we added two service-specific dummies for intercity and mixed firms, so as to consider possible shifts of frontier cost levels due to different network configurations. Dummy DINTC assumes value 1 for intercity companies and 0 otherwise, similarly $D M I X$ is equal to 1 in the case of mixed operators and 0 for specialized networks.

Finally, we included a time trend in the model, measured in years, so as to account for possible effects of Hicks neutral technological change. In fact, given the seven-year length of the panel the impact of scientific or organizational progress should not be negligible. Assuming the other things are unchanged, costs are then expected to diminish over time.

A translog functional form is chosen for this analysis. ${ }^{13}$ The stochastic frontier cost model [1]-[2] is then defined by equation [3]:

$$
\begin{aligned}
\ln \left(\frac{V C_{f t}}{P_{F f t}}\right) & =\beta_{0}+\beta_{y} \ln Y_{f t}+\beta_{k} \ln K_{f t}+\sum_{i} \beta_{i} \ln \left(\frac{P_{i f t}}{P_{F f t}}\right)+\beta_{S P} \ln S P_{f t}+\sum_{i} \beta_{i y} \ln \left(\frac{P_{i f t}}{P_{F f t}}\right) \ln Y_{f t}+ \\
& +\sum_{i} \beta_{i k} \ln \left(\frac{P_{i f t}}{P_{F f t}}\right) \ln K+\sum_{i} \beta_{i S P} \ln \left(\frac{P_{i f t}}{P_{F f t}}\right) \ln S P_{f t}+\beta_{y k} \ln Y_{f t} * \ln K_{f t}+ \\
& +\beta_{y S P} \ln Y_{f t} * \ln S P_{f t}+\beta_{k S P} \ln K_{f t} * \ln S P_{f t}+\frac{1}{2} \beta_{y y}\left(\ln Y_{f t}\right)^{2}+\frac{1}{2} \beta_{k k}\left(\ln K_{f t}\right)^{2}+ \\
& +\frac{1}{2} \beta_{S P S P}\left(\ln S P_{f t}\right)^{2}+\frac{1}{2} \sum_{i} \sum_{j} \beta_{i j} \ln \left(\frac{P_{i f t}}{P_{F f t}}\right) \ln \left(\frac{P_{j f t}}{P_{F f t}}\right)+ \\
& +\beta_{I N T C} D I N T C_{f t}+\beta_{M I X} D M I X_{f t}+\beta_{\tau} \tau_{f t}+v_{f t}+u_{f t} \\
& i, j \in\{L, M S\},
\end{aligned}
$$

where the normalization of the monetary variables, $V C, P_{L}$ and $P_{M S}$, with respect to the price of fuel, $P_{F}$, is made to ensure the linear homogeneity of the cost function in input prices. ${ }^{14}$

The X-inefficiency term, $u_{f t}$, reflects the inability of firm $f$ at the observation $t$ to attain the potential minimum cost defined by the stochastic frontier. The specification for this effect

\footnotetext{
${ }^{13}$ Given the regularity conditions ensuring duality, the estimation of a translog cost function does not impose any other a priori restriction on the characteristics of the below technology. In particular, the elasticity of substitution and the returns to scale can vary with both the output level and the combination of inputs. This fully satisfies the criterion of model generality.

${ }^{14}$ Symmetry property $\left(\beta_{i j}=\beta_{j i}\right.$ for all $\left.i, j\right)$ is also imposed a priori, whereas the other regularity conditions, viz., monotonicity of the cost function in input prices and output, and concavity in input prices are checked ex-post.
} 
and the discussion of the estimation technique for the final stochastic frontier model are given in the next two sections.

\subsection{Modeling inefficiency effects}

Several innovations concerning the estimation of inefficiency using the stochastic production and cost frontier approach have been introduced since the pioneer contributions of Aigner, Lovell and Schmidt (1977) and Meeusen and van den Broeck (1977). ${ }^{15}$ In particular, a number of later empirical studies (e.g., Pitt and Lee, 1981; Kalirajan, 1981; Kalirajan and Shand, 1989; Mester, 1997) have investigated the determinants of productive inefficiencies among firms in an industry by regressing the predicted inefficiency effects, obtained from an estimated stochastic frontier, upon a vector of firm-specific factors, such as the degree of competitive pressure, input and output quality indicators, various managerial characteristics, etc., in a second-stage analysis. There is, however, a significant problem with this two-stage approach. In the first stage, the inefficiency effects are assumed to be independently and identically distributed in order to use the approach of Jondrow et al. (1982) to predict the values of the technical inefficiency effects. However, in the second stage, the predicted inefficiency effects are assumed to be a function of a number of firm-specific factors, which implies that they are not identically distributed, unless all the coefficients of the factors are simultaneously equal to zero.

Kumbhakar, Ghosh and McGuckin (1991) and Reifschneider and Stevenson (1991) noted the above inconsistency and specified stochastic frontier models in which the inefficiency effects were defined as explicit functions of some firm-specific factors, and all parameters were estimated in a single-stage maximum likelihood (ML) procedure. Huang and Liu (1994) also presented a model for a stochastic frontier production function, in which the non-negative technical inefficiency effects were a linear function of variables involving firm characteristics, together with their interactions with the input variables of the frontier function. ${ }^{16}$ Battese and Coelli $(1993,1995)$ extended these approaches to accommodate for panel data, which makes it possible to include both firm-specific and time effects in the model adopted to explain inefficiencies.

Using the «FRONTIER Version 4.1» computer program by Coelli (1996), this study applies the Battese and Coelli (1995) methodology for analysing the effects of regulatory constraints on the cost efficiency of public transit systems in Italy. ${ }^{17}$ The objective, in particular, is to investigate whether the predictions from the theory of incentives in regulation (Laffont and Tirole, 1993) help to explain differences in productive efficiency, i.e. do high

\footnotetext{
${ }^{15}$ An up-to-date and detailed review of the literature on stochastic frontier modeling and efficiency measurement is provided in Kumbhakar and Lovell (2000).

${ }_{16}$ This makes their model a non-neutral shift of the traditional average response function, in that the marginal products of inputs and marginal rates of technical substitution (MRTS) depend on the firm-specific variables in the inefficiency model.

17 This software allows us to specify the stochastic frontier in terms of a dual cost relationship instead of a production function and it also enables us to use unbalanced panel data.
} 
powered incentive regulatory schemes increase efficiency as compared to low powered schemes? To do this, we start from issues of a stochastic cost frontier model recently developed by Gagnepain and Ivaldi (2002a). ${ }^{18}$ We postpone to the following section the discussion concerning the statistical properties of the Battese and Coelli (1995) econometric model and the estimation procedure. In succession, the principal features of the Gagnepain and Ivaldi (2002a) model are briefly resumed, focusing the attention on the role of informational asymmetries and incentives in the regulator-firm relationship. Then we describe the variables we suppose capture these effects within the methodological framework proposed by Battese and Coelli.

From equations [1]-[2] overall cost inefficiency could be defined by the expression $\exp \left\{u_{f t}\right\}$, which represents the extent to which observed cost, $V C_{f t}$, exceeds the frontier minimum level after accounting for the effect of statistical noise, $V C\left(Y_{f t}, P_{f t}, Z_{f t}, \tau_{f t} ; \beta\right) \exp \left\{v_{f t}\right\}$. Gagnepain and Ivaldi specified $u_{f t}$ as $g\left(\theta_{f t}, e_{f t}\right)$, so that $\exp \left\{u_{f t}\right\}=\exp \left\{g\left(\theta_{f t}, e_{f t}\right)\right\}$, where $g$ is a function strictly increasing in $\theta$ and decreasing in $e,{ }^{19} \theta$ is a parameter reflecting the presence of exogenous technical inefficiency, which implies a fall in the productivity of labor input, ${ }^{20}$ and $e$ represents the cost-reducing activity exerted by managers to counterbalance the effect of the intrinsic lack of labor productivity. ${ }^{21}$

The intrinsic labor inefficiency, $\theta$, is supposed to be perfectly known by the firm and not known or imperfectly known by the regulatory authority (adverse selection phenomenon), as the latter does not take part in the production process. On the other hand, it should be even harder for the regulator-principal to observe and directly control the effort provided by the manager-agent, $e$ (moral hazard phenomenon). ${ }^{22}$ Since there is no clear evidence on the motivation of a manager to work as hard as he could, it is precisely in this context that the type of regulatory scheme and related incentives faced by the firm during the production process play a role in reducing overall cost inefficiency, $\exp \{g(\theta, e)\}$.

\footnotetext{
${ }^{18}$ These authors utilize an economic-theory-based (or structural) approach and directly incorporate into the cost minimization problem the distortions on productive activity due to regulatory constraints and the presence of informational asymmetries in the regulator-firm interaction. In this way, the error component that the literature generally attributes to cost inefficiency, $u_{f}$, is already built-in and the econometric frontier model exactly coincides with the theoretical cost model, without the necessity of adding anything more than a random disturbance term to account for exogenous shocks and potential measurement faults. However, for interpretability and tractability, they adopt a simple Cobb-Douglas technology. As the authors recognize, this functional form "may not be the best choice for achieving a good approximation of the true cost function", even though it allow them to derive closed form solutions.

${ }^{19}$ Subscripts $f$ and $t$ are omitted for convenience in the presentation.

${ }^{20}$ This type of inefficiency is given and cannot be changed by the management in the short run. It depends on factors such as the geographical and historical characteristics of a network, the structure of the labor force or the ability level of drivers.

${ }^{21}$ The operator may spend time and effort on monitoring workers, for instance providing drivers with training programs, solving potential conflicts among them, avoiding strikes, etc. It is worthwhile to underline that, unless the effort level of managers fully offsets labor inefficiency, i.e. $(\theta-e)$ goes to zero, the firm minimizes costs by taking into account a higher labor price. That is, the MRTS of any pair of inputs containing labor is higher than the observed price ratio of inputs, which may lead to cost inefficiencies.

${ }^{22}$ Indeed, the regulator cannot distinguish between the effect of intrinsic inefficiency and the impact of costreducing effort.
} 
The authors elaborated a structural cost frontier model, in which the cost-reducing effort of the producer is endogenous in the sense that it depends on the regulatory environment impinging on its activity. By applying this model to the analysis of public transit systems in France (Gagnepain and Ivaldi, 2002a and 2002b) they showed that operators subjected to fixed-price subsidization schemes exhibited higher effort levels compared to ones displayed by companies run under cost-plus mechanisms. ${ }^{23}$ Given the level of intrinsic inefficiency, this implied lower cost distortions over the best-practice frontier, and the fact that fixed-price contracts provide more incentive for efficiency has been proved. Contractual arrangements did not appear to be very relevant for the firm's productive performance only for a group of operators characterized by a fairly high technical inefficiency. Indeed, in these cases the costreducing activity exerted by managers has little weight in determining global cost inefficiency. Consequently, the distortions over the frontier remain significant also in the presence of high powered incentive schemes.

Taking cue from the above results, the Battese and Coelli (1995) stochastic frontier model is applied to the analysis of overall cost inefficiency, or X-inefficiency, of public transit systems in Italy. The emphasis is put on the role played by the regulatory context, in terms of the different subsidization mechanisms that companies have to face, also taking into account the specific characteristics of each network in a way which will be specified later.

Battese and Coelli define the inefficiency effects, $u_{f t}$, as non-negative random variables assumed to be a function of a set of firm-specific explanatory variables which may vary over time, $z_{f t}$, and an unknown vector of coefficients, $\delta$, associated with the $z_{f t} s$. The explanatory variables in the inefficiency model would be expected to include any factors that help explain the extent to which the variable cost observations exceed the corresponding stochastic frontier cost values, $V C\left(Y_{f t}, P_{f t}, Z_{f t}, \tau_{f t} ; \beta\right) \exp \left\{v_{f t}\right\}$.The $z_{f t}$-vectors usually have the first element equal to one $^{24}$ and may also include some variables involved in the cost function ${ }^{25}$ and/or interactions between these latter and firm-specific factors.

The X-inefficiency effect, $u_{f t}$, incorporated in the composed error term, $\psi_{f t}$, of the general stochastic frontier model [1]-[2] could be specified by equation [4],

$$
u_{f t}=\delta^{\prime} z_{f t}+w_{f t}=\sum_{q} \delta_{q} z_{q f t}+w_{f t}
$$

where the $q$ subscript on $\delta$ and $z_{f t}$ indexes explanatory variables $(q=0, \ldots, Q)$, and $w_{f t}$ is a random variable making the inefficiency effect stochastic, whose distribution will be defined in the next section.

\footnotetext{
${ }^{23}$ This evidence is consistent with the new theory of regulation (Laffont and Tirole, 1993) which defines the fixed-price schemes as the maximal powered incentive contracts. More precisely, the optimal effort level equalizes the marginal disutility of effort and the marginal cost savings under fixed-price regimes while it is nil under cost-plus regimes.

${ }^{24}$ Not including an intercept parameter, $\delta_{0}$, in the $z_{f t}$-vectors may result in the estimators for the $\delta$-parameters being biased and the shape of the distributions of the inefficiency effects, $u_{f t}$, being unnecessarily restricted.

${ }^{25}$ Provided the inefficiency effects are stochastic.
} 
Since our objective is to verify whether the causes of cost inefficiency affecting the Italian public transit systems should be searched for in the system of incentives generated by the regulatory environment, we first introduce a regulation dummy, $R_{f t}$, as determinant of $u_{f t}$.

As previously mentioned, two great categories of reimbursement rules are observed in practice: cost-plus schemes, according to which subsidies are paid by the local authority to the company so as to allow ex-post budgets to be balanced, ${ }^{26}$ and fixed-price schemes, where the transit operator obtains a transfer defined ex-ante in order to finance an expected operating deficit. ${ }^{27}$ Variable $R_{f t}$ takes value 0 when cost-plus regulation is observed, and value 1 in cases where fixed-price schemes are applied. According to the predictions from the theory of incentives in regulation and the evidence emerging in the study of Gagnepain and Ivaldi, cost distortions over the frontier, $\exp \left\{u_{f t}\right\}$, are expected to be significantly lower under fixed-price regulation, because in such a context the company's manager should increase the effort to reduce production costs. The sign of the parameter associated with the regulation dummy, $\delta_{R}$, is then expected to be negative.

The second important explanatory variable we include in the specification of the cost inefficiency model [4] aims at capturing the effects on X-efficiency attributable to the specific operating conditions of the environment where the transit service is provided. We refer to factors such as the geographical and historical characteristics influencing the structure and the operability of the network, the ability level of drivers, the public policy for local mobility, etc. These are the elements that in the Gagnepain and Ivaldi model contribute to determine the intrinsic labor inefficiency level, $\theta_{f t}$, what the authors call "exogenous technical inefficiency".

Here we do not obtain a specific estimate for this unobservable component of the global cost inefficiency. ${ }^{28}$ However, an attempt is made to include in the inefficiency model [4] a variable strictly related to the above factors (hereafter "network characteristics"), likely to influence the exogenous technical inefficiency and then the level of overall cost distortion. To this end we introduce as a proxy for network characteristics the average commercial speed, ln $S P_{f t}$, already included in the specification of the frontier cost function as a network variable affecting the underlying technology. ${ }^{29}$ Since a higher value for this variable is supposed to reflect better operating conditions, ${ }^{30}$ thus reducing the intrinsic inefficiency level, once the

\footnotetext{
${ }^{26}$ In Section 2 we refer to this reimbursement rule as the "management contract", under which the regulated firm does not bear any risk.

${ }^{27}$ This type of reimbursement rule specifically refers to the subsidization scheme we have previously called "net cost contract". Actually, we have seen that the class of fixed-price schemes also includes the "gross cost contract". Under this variant, the authority receives the commercial revenue and pays the firm's expected costs. In terms of incentives to produce efficiently, it is similar to the first variant of fixed-price contracts. Under the "net cost contract" option, however, the LPT operator bears all the risks on costs (industrial risk) and revenue (commercial risk), whereas under the "gross cost contract" option only the industrial risk is borne by the transit firm.

${ }^{28}$ Indeed, we remark that $\theta$ represents an adverse selection parameter which reflects private information on the firm's technology that is not known (or imperfectly known) by the regulatory authority and the econometricians.

${ }^{29}$ Transformation in logarithms is maintained for homogeneity with the equation [3]. In both cases the logarithm specification enables the interpretation of the partial derivatives of the dependent variables, $\ln V C_{f t}$ and $u_{f t}$, computed with respect to $\ln S P_{f t}$ in terms of elasticities.

${ }^{30}$ In fact, it is reasonable to assume that the average commercial speed may increase for instance when transit firms face more favorable geographical conditions, skilful drivers, or public policies attentive to the local traffic
} 
positive relationship between $\theta_{f t}$ and $u_{f t}$ conjectured in the Gagnepain and Ivaldi model is assumed to be valid, we expect to find a negative sign for the coefficient associated with $\ln S P_{f t}, \delta_{S P}$, in model [4].

Furthermore, in order to take into account the evidence that when the intrinsic inefficiency of a network is too high, the effect of contractual arrangements on the overall cost inefficiency becomes modest, the impact exerted by regulatory schemes is allowed to vary with the level of average commercial speed. This is made by introducing in the model an interaction of the regulation dummy with the variable $\ln S P_{f t}$, denoted $\left(R_{f t} \times \ln S P_{f t}\right)$. The relative parameter, $\delta_{R S P}$, is expected to have a negative sign, to indicate a stronger power of fixedprice schemes in reducing X-inefficiency when regulated firms are facing more favourable exogenous operating conditions. At the same time, the negative sign of $\delta_{R S P}$ would mean that the impact on cost efficiency due to a gain in the average commercial speed is strengthened in the presence of fixed-price schemes, because of the higher cost-reducing effort provided by managers under this type of regulation.

As the Battese and Coelli model enables us to include both firm-specific and time effects in the specification of the inefficiency model, we also incorporate in the equation [4] a time variable, $\tau_{f t}$, indicating the year of the observation involved. It specifies that X-inefficiency may change linearly with respect to time according to the sign of the associated parameter, $\delta_{\tau}$. Given the frequent government stopgap measures adopted in the first half of the nineties to face deficits of LPT companies and the delays in bringing about the reform that began with the Law n. 549 in 1995, the sign of this coefficient is expected to be positive. Moreover, an interaction between regulation dummy and time variable is also introduced, so as to allow the dynamics of cost inefficiencies throughout the analyzed period to vary with the regulatory pattern. We denote this variable with $\left(R_{f t} \times \tau_{f t}\right)$, while $\delta_{R \tau}$ is the relative parameter.

Under the above specifications on the set of explanatory variables, the $z_{f t} s$, the cost inefficiency model [4] can be written as

$$
u_{f t}=\delta_{0}+\delta_{R} R_{f t}+\delta_{S P} \ln S P_{f t}+\delta_{\tau} \tau_{f t}+\delta_{R S P}\left(R_{f t} \times \ln S P_{f t}\right)+\delta_{R \tau}\left(R_{f t} \times \tau_{f t}\right)+w_{f t} .
$$

Equation [5] indicates that stochastic X-inefficiency effects are linearly related to the regulatory scheme and commercial speed of the transit companies, the period of observation, and the interactions of speed and time with regulation, with an intercept parameter, $\delta_{0}$, included in the model.

\subsection{Distributional assumptions and estimation procedure}

The final stochastic frontier model to be estimated is specified in equation [3], where the cost inefficiency effects, $u_{f t}$, are defined by expression [5]. According to Battese and Coelli (1995), the following distributional assumptions are made for the two components of the global error term, $\psi_{f t}$ :

regulation. 
(i) the random noises $v_{f t} s$ are assumed $\sim$ i.i.d. $N\left(0, \sigma_{v}{ }^{2}\right)$, independently distributed of the cost inefficiency effects, the $u_{f t} s$;

(ii) the $u_{f t} s$ are non-negative random variables, which are assumed to be independently but not identically distributed, so that $u_{f t}$ arises from the truncation (at zero) of the normal distribution with mean $\delta^{\prime} z_{f t}$ and variance $\sigma_{u}{ }^{2}, N\left(\delta^{\prime} z_{f t}, \sigma_{u}{ }^{2}\right)$. This can also be written as $u_{f t} \sim$ $N^{+}\left(\delta^{\prime} z_{f t}, \sigma_{u}{ }^{2}\right)$, where $N^{+}\left(\delta^{\prime} z_{f t}, \sigma_{u}{ }^{2}\right)$ indicates a truncated-normal distribution with mode $\delta^{\prime} z_{f t}$ and spread parameter $\sigma_{u}{ }^{2}$. This assumption allows individual cost inefficiencies to depend on firm- and time-specific exogenous observable factors, $z_{f t}{ }^{31}$

The ML method is employed for the simultaneous estimation of parameters of the stochastic frontier [3] and the model for the cost inefficiency effects [5]. Using the above distributional assumptions on $v_{f t}$ and $u_{f t}$, the log-likelihood function for the $\left(T_{1}+T_{2}+\ldots+T_{F}\right)$ sample observations, $\ln V C=\left(\ln V C_{11}, . ., \ln V C_{1 T 1} ; \ln V C_{21}, . ., \ln V C_{2 T 2} ; \ldots ; \ln V C_{F 1}, . ., \ln V C_{F T F}\right)^{\prime}$, can be written as

$$
\begin{aligned}
L\left(\beta, \delta, \sigma^{2}, \gamma ; \ln V C\right)= & -\frac{1}{2}\left(\sum_{f=1}^{F} T_{f}\right)\left\{\ln 2 \pi+\ln \sigma^{2}\right\} \\
& -\frac{1}{2} \sum_{f=1}^{F} \sum_{t=1}^{T_{f}}\left\{\left[\ln V C_{f t}-\ln V C\left(Y_{f t}, P_{f t}, Z_{f t}, \tau_{f t} ; \beta\right)-\delta^{\prime} z_{f t}\right]^{2} / \sigma^{2}\right\} \\
& -\sum_{f=1}^{F} \sum_{t=1}^{T_{f}}\left\{\ln \Phi\left[d_{f t}\right]-\ln \Phi\left[d_{f t}^{*}\right]\right\},
\end{aligned}
$$

where $\Phi(\cdot)$ is the standard normal cumulative distribution function, $d_{f t}=\delta^{\prime} z_{f t} /\left(\gamma \sigma^{2}\right)^{1 / 2}$, and $d_{f t}^{*}=\left[(1-\gamma) \delta^{\prime} z_{f t}+\gamma\left(\ln V C_{f t}-\ln V C\left(Y_{f t}, P_{f t}, Z_{f t}, \tau_{f t} ; \beta\right)\right)\right] /\left[\gamma(1-\gamma) \sigma^{2}\right]^{1 / 2}$.

The log-likelihood function is formulated in terms of the parameterization suggested by Battese and Corra (1977) who replace $\sigma_{v}{ }^{2}$ and $\sigma_{u}{ }^{2}$ with $\sigma^{2} \equiv\left(\sigma_{v}{ }^{2}+\sigma_{u}{ }^{2}\right)$ and $\gamma \equiv \sigma_{u}{ }^{2} /\left(\sigma_{v}{ }^{2}+\sigma_{u}{ }^{2}\right)$. The parameter $\gamma$ must lie between 0 and 1 and provides a useful indication of the relative contributions of $u_{f t}$ and $v_{f t}$ to $\psi_{f t}$. As $\gamma \rightarrow 0$ the symmetric noise component, $v_{f t}$, dominates the one-sided cost inefficiency term, $u_{f t}$, in determining the variation of global residual, $\psi_{f t}$. The inverse occurs as $\gamma \rightarrow 1$. In the former case we are back to a traditional average cost function model with no stochastic inefficiency, whereas in the latter case we are back to a deterministic cost frontier model with no random noise included. ${ }^{32}$ The derivation of the log-likelihood function [6] is presented in the Appendix. ${ }^{33}$

After obtaining parameter estimates, we consider the estimation of $u_{f t}$. When the model in equation [4] is assumed, the overall cost inefficiency of production for the $f^{\text {th }}$ firm at the $t^{\text {th }}$ observation is defined by expression [7],

\footnotetext{
${ }^{31}$ With regards to the concepts of half-normal and truncated-normal distribution see Kumbhakar and Lowell (2000), pages 74-86.

${ }^{32}$ The term deterministic is used because in this type of frontier model the observed cost, $V C_{f t}$, is bounded below by a non-stochastic (i.e. deterministic) minimum quantity, $V C\left(Y_{f t}, P_{f t}, Z_{f t}, \tau_{f t} ; \beta\right)$. The models of Aigner and Chu (1968), Afriat (1972) and Schmidt (1976) are examples of deterministic frontiers.

${ }^{33}$ The presentation follows the Appendix of Battese and Coelli (1993), excepting a few simple sign changes to take into account that we are working with a cost frontier instead of a production frontier model.
} 


$$
C I_{f t}=\exp \left\{u_{f t}\right\}=\exp \left\{\delta^{\prime} z_{f t}+w_{f t}\right\},
$$

which takes a value between one (when $u_{f t}=0$ ) and infinity (when $u_{f t} \rightarrow \infty$ ). The prediction of the x-inefficiencies, $C \hat{I}_{f t}$, is based on conditional expectations which generalize the estimators in Jondrow et al. (1982) and Battese and Coelli (1988). This result is also provided in the Appendix. $^{34}$

\section{Data description}

The study uses a seven-year unbalanced panel data of 45 companies operating in the Italian LPT sector that spans the period from 1993 to 1999 and are members of ASSTRA. ${ }^{35}$ More precisely, the panel includes 31 units observed in the years 1993-1995 and 1999 and 45 units in the period 1996-1998, for a total of 259 observations.

The sample composition by type of service is the following: of the 45 analyzed firms, 18 mostly operate in the urban context, 15 mainly provide intercity service, and the remaining 12 have activities in both compartments. As far as the distribution by geographical area is concerned, the sample is fairly balanced: 25 operators are located in the North regions and 20 in the Center-South regions (in particular, 10 in the Center and 10 in the South). The prevalence in the sample of companies providing only bus service (37 units) compared to the multi-modal firms (including also tramways, trolley-lines, and railways) reflects the modality composition at national level, where the road mode of transportation represents about $80 \%$ of LPT services in terms of seat-kilometers. ${ }^{36}$ As for firm size, measured in terms of the average number of employed workers, the sample includes 12 large-sized firms (more than 550 workers), 23 medium-sized units (151-550 workers), and 10 small operators (less than 150 workers). Finally, as far as the subsidization mechanisms are concerned, twenty-seven percent of observations (71 cases) relate to fixed-price regulatory schemes, while seventy-three percent (188 cases) refer to transit systems under cost-plus reimbursement rules.

For the panel construction we resorted to two different informational sources. The starting database gathers information extracted from ASSTRA annual reports concerning the years indicated above. From these reports we were able to derive the main economic and productive data for each company in the sample, such as global production cost, labor cost, traveled kilometers, rolling stock size, average number of workers, and fuel consumption. The data was appropriately integrated by further information on cost, technical-environmental factors and type of regulatory scheme obtained through questionnaires sent to the companies. This additional investigation enabled the cost to be split by productive factors other than

\footnotetext{
${ }^{34}$ It is worthwhile pointing out that $\left(\delta^{\prime} z_{f t}+w_{f t}\right)>\left(\delta^{\prime} z_{f^{\prime} t}+w_{f^{\prime} t}\right)$ for $f \neq f^{\prime}$ does not necessary imply that $\left(\delta^{\prime} z_{f t^{\prime}}+w_{f t^{\prime}}\right)$ $>\left(\delta^{\prime} z_{f^{\prime} t^{\prime}}+w_{f^{\prime} t^{\prime}}\right)$ for $t \neq t^{\prime}$. Thus it follows that the same ordering of firms in terms of cost inefficiency of production does not apply to all time periods.

${ }^{35}$ ASSTRA (Rome) is a nationwide trade organization which associates the Italian publicly-owned LPT firms. In 1998 , the company members of ASSTRA came to around 155 , equal to $90 \%$ of the urban operators and to $50 \%$ of the intercity operators in Italy. The sample we use may then be considered to be sufficiently representative.

${ }^{36}$ Source: Ministry of Transports and Navigation (1997). in the model
} 
labor, such as capital, fuel, and materials and services. Moreover, we retrieved relevant technical information (average load capacity and commercial speed of LPT vehicles, network size, average fleet age), in order to complement the data extracted from the ASSTRA annual reports. To analyze the effects of regulatory schemes on X-efficiency, we need information which encompasses both the performance and the subsidization of the Italian public transit systems. To this end, we also included in the questionnaire a question on the reimbursement mechanism adopted by the competent local authority (Region, Province or Town Council). ${ }^{37}$ This rich source is probably unique in Italy as a tool of comparing regulatory systems to each other and over time.

\section{Empirical results}

ML estimates of the parameters of the model defined in [3]-[5] are given in Tables $1 \mathrm{a}$ and $1 \mathrm{~b}$. In particular, Table 1a reports the estimated coefficients, $\beta$, for the stochastic frontier cost function [3], while Table 1b presents the estimates of the inefficiency-related coefficients, $\delta$, for the model [4] and the two variance parameters, $\gamma$ and $\sigma^{2}$. The results are given in the second column of Tables 1a and 1b, indicated by Full Model. The third column of Tables 1a and $1 \mathrm{~b}$, indicated by Restricted Model, reports the ML estimates for the parameters of the "preferred" frontier model, to be discussed below, in which some coefficients in the general specification [3]-[5] are restricted to be zero.

The signs of the first-order $\beta$ parameters are all as expected, with the exception of the positive estimate for the quasi-fixed input coefficient, $\beta_{k}$. In fact, the evidence that the variable costs increase with larger rolling stocks is not consistent with the microeconomic theory. ${ }^{38}$ An intense debate has arisen in literature on this problem. According to Filippini (1996), the positive sign of $K$ is due to a problem of multicolinearity in cases where a positive correlation between dependent variable and capital indicator exists. The alternative argument put forward by Caves, Christensen, Tretheway and Windle (1985) and Windle (1988) is that the positive sign of $K$ reflects an industry that does not minimize cost in the long term and therefore employs too much capital in the production process. This interpretation has also been proposed in a later study on the Italian urban transit systems carried out by Levaggi (1994). In this work the author argues that the inefficient use of capital could derive from the generous government programs of subsiding investments. This way of providing funds to purchase capital distorted the input allocation.

\footnotetext{
${ }^{37}$ In particular, we asked the company to specify for each observed year if the subsidization was cost-plus (i.e., management contract) or fixed-price (i.e., net/gross cost contract) oriented. The answers were then checked by a direct telephone talk with the operators and a discussion with the juridical consultant of ASSTRA.

${ }^{38}$ A variable cost function should also satisfy the property that is non-increasing with respect to capital stock (see Cornes, 1992, p. 106). It is worthwhile noticing that the wrong sign estimated for the capital coefficient seems to be a general problem characterizing the use of a variable cost function model, not only in the studies on transportation industry.
} 
Table 1a. Maximum-likelihood estimates for parameters of the stochastic frontier cost function [3]*

\begin{tabular}{|c|c|c|}
\hline Parameter & Full Model & Restricted Model \\
\hline$\beta_{0}$ & $\begin{array}{l}18.193 \\
(0.047)\end{array}$ & $\begin{array}{l}18.248 \\
(0.033)\end{array}$ \\
\hline$\beta_{y}$ & $\begin{array}{c}0.445 \\
(0.046)\end{array}$ & $\begin{array}{c}0.530 \\
(0.015)\end{array}$ \\
\hline$\beta_{k}$ & $\begin{array}{c}0.214 \\
(0.097)\end{array}$ & $\begin{array}{c}0.032 \\
(0.029)\end{array}$ \\
\hline$\beta_{L}$ & $\begin{array}{c}0.655 \\
(0.129)\end{array}$ & $\begin{array}{c}0.655 \\
(0.102)\end{array}$ \\
\hline$\beta_{M S}$ & $\begin{array}{c}0.287 \\
(0.043)\end{array}$ & $\begin{array}{c}0.255 \\
(0.021)\end{array}$ \\
\hline$\beta_{S P}$ & $\begin{array}{l}-0.201 \\
(0.055)\end{array}$ & $\begin{array}{l}-0.185 \\
(0.038)\end{array}$ \\
\hline$\beta_{L y}$ & $\begin{array}{c}0.391 \\
(0.138)\end{array}$ & $\begin{array}{c}0.331 \\
(0.099)\end{array}$ \\
\hline$\beta_{M S y}$ & $\begin{array}{c}0.038 \\
(0.048)\end{array}$ & 0 \\
\hline$\beta_{L k}$ & $\begin{array}{c}-0.855 \\
(0.298)\end{array}$ & $\begin{array}{l}-0.728 \\
(0.214)\end{array}$ \\
\hline$\beta_{M S k}$ & $\begin{array}{l}-0.108 \\
(0.098)\end{array}$ & 0 \\
\hline$\beta_{y y}$ & $\begin{array}{c}-0.048 \\
(0.055)\end{array}$ & 0 \\
\hline$\beta_{k k}$ & $\begin{array}{l}-0.335 \\
(0.119)\end{array}$ & $\begin{array}{l}-0.105 \\
(0.027)\end{array}$ \\
\hline$\beta_{y k}$ & $\begin{array}{c}0.258 \\
(0.109)\end{array}$ & $\begin{array}{c}0.047 \\
(0.013)\end{array}$ \\
\hline$\beta_{L M S}$ & $\begin{array}{c}-0.071 \\
(0.188)\end{array}$ & 0 \\
\hline$\beta_{L L}$ & $\begin{array}{c}0.594 \\
(0.287)\end{array}$ & $\begin{array}{c}0.754 \\
(0.226)\end{array}$ \\
\hline$\beta_{M S M S}$ & $\begin{array}{c}0.121 \\
(0.043)\end{array}$ & $\begin{array}{c}0.065 \\
(0.035)\end{array}$ \\
\hline$\beta_{y S P}$ & $\begin{array}{c}0.026 \\
(0.052)\end{array}$ & 0 \\
\hline$\beta_{k S P}$ & $\begin{array}{c}-0.142 \\
(0.072)\end{array}$ & $\begin{array}{l}-0.083 \\
(0.024)\end{array}$ \\
\hline$\beta_{L S P}$ & $\begin{array}{l}-0.490 \\
(0.142)\end{array}$ & $\begin{array}{l}-0.438 \\
(0.138)\end{array}$ \\
\hline$\beta_{M S P}$ & $\begin{array}{c}0.224 \\
(0.058)\end{array}$ & $\begin{array}{c}0.175 \\
(0.052)\end{array}$ \\
\hline$\beta_{S P S P}$ & $\begin{array}{l}-0.127 \\
(0.070)\end{array}$ & $\begin{array}{l}-0.184 \\
(0.067)\end{array}$ \\
\hline$\beta_{\text {INTC }}$ & $\begin{array}{l}-0.055 \\
(0.027)\end{array}$ & $\begin{array}{l}-0.088 \\
(0.031)\end{array}$ \\
\hline$\beta_{M I X}$ & $\begin{array}{l}-0.107 \\
(0.030)\end{array}$ & $\begin{array}{l}-0.129 \\
(0.026)\end{array}$ \\
\hline$\beta_{\tau}$ & $\begin{array}{l}-0.014 \\
(0.005)\end{array}$ & $\begin{array}{l}-0.015 \\
(0.004)\end{array}$ \\
\hline
\end{tabular}

* Estimated asymptotic standard errors are given in parentheses. All the independent variables except for time have been normalized to their sample mean value before the transformation in logarithms. 
As for the second-order $\beta$ coefficients, it can be observed that the effects of the interaction of $P_{M S}$ with $Y, K$ and $P_{L}$, the interaction between $Y$ and $S P$, and the quadratic term for $Y$, are very weak. Indeed, the estimated parameters, $\beta_{M S y}, \beta_{M S k}, \beta_{L M S}, \beta_{y S P}$, and $\beta_{y y}$ are all small and less than their estimated standard errors, so that asymptotic t-tests lead to the acceptance of the null hypothesis of zero value for each of them. ${ }^{39}$

Table 1b. Maximum-likelihood estimates for parameters of the stochastic cost inefficiency model [5]*

\begin{tabular}{c|cc}
\hline Parameter & Ful ModeI & Restricted Model \\
\hline$\delta_{0}$ & 0.841 & 0.677 \\
$\delta_{R}$ & $(0.405)$ & $(0.270)$ \\
\multirow{2}{*}{$\delta_{S P}$} & -0.573 & -0.868 \\
$\delta_{\tau}$ & $(0.226)$ & $(0.306)$ \\
\multirow{2}{*}{$\delta_{R S P}$} & -0.878 & -0.543 \\
\multirow{2}{*}{$\delta_{R \tau}$} & $(0.334)$ & $(0.154)$ \\
\multirow{2}{*}{$\sigma^{2}$} & 0.058 & 0.059 \\
& $(0.025)$ & $(0.021)$ \\
$\gamma^{*}$ & -0.709 & -0.976 \\
& $(0.319)$ & $(0.482)$ \\
Log-likelihood & -0.024 & 0 \\
& $(0.046)$ & 0.082 \\
& 0.084 & $(0.024)$ \\
& $(0.029)$ & 0.966 \\
& 0.958 & $(0.015)$ \\
\hline
\end{tabular}

* Estimated asymptotic standard errors are given in parentheses. Variable SP has been normalized to its sample mean value and transformed in logarithms.

The $\delta$ coefficients associated with the explanatory variables in the inefficiency model [5] are of particular interest to this study. Inspection of Table $1 \mathrm{~b}$, second column, reveals that the parameters have the right sign and are almost all statistically significant at the 1 or 5 percent level of significance. The only exception is the estimate for the coefficient associated with the interaction between regulation dummy and time, $\delta_{R \tau}$. This parameter assumes a negative sign, which would indicate that the annual increase in X-inefficiency (highlighted by the positive sign of $\delta_{\tau}$ ) is less marked when firms face fixed-price regulatory schemes. However, its magnitude, -0.024 , is small compared to the estimated standard error, 0.046 , so the coefficient appears statistically insignificant. It is worthwhile observing that the above interaction may also be interpreted as allowing the differential impact of regulation on cost inefficiency to depend on time. In this case, accepting the null hypothesis of zero value for $\delta_{R \tau}$ and rejecting that it is significantly less than zero would imply that the effects of regulatory schemes are not statistically different across the years, in particular the power of fixed-price contracts to reduce inefficiency does not become stronger with the passage of time.

\footnotetext{
${ }^{39}$ Unless otherwise stated, all tests of hypothesis in this study are conducted at the $5 \%$ level of significance.
} 
The remaining two parameters in Table $1 \mathrm{~b}, \sigma^{2} \equiv\left(\sigma_{v}{ }^{2}+\sigma_{u}{ }^{2}\right)$ and $\gamma \equiv \sigma_{u}{ }^{2} /\left(\sigma_{v}{ }^{2}+\sigma_{u}{ }^{2}\right)$, are associated with the variances of the random noise, $v_{f t}$, and the inefficiency term, $u_{f t}$. We note, in particular, that the estimate for $\gamma$ is 0.958 with an asymptotic standard error of 0.015 , which indicates that the vast majority of residual variation is due to the $\mathrm{X}$-inefficiency effects and these are likely to be highly significant in the analysis of the cost performance of the Italian LPT companies.

Table 2. Likelihood-ratio tests of hypotheses for parameters of the stochastic frontier cost function [3] and the cost inefficiency model [5]

\begin{tabular}{|c|c|c|c|}
\hline Null hypothesis & $\begin{array}{c}\text { Log- } \\
\text { likelihood }\end{array}$ & $\begin{array}{c}\chi^{2}- \\
\text { statistic }\end{array}$ & Decision \\
\hline$H_{0}: \gamma=\delta_{0}=\delta_{R}=\delta_{S P}=\delta_{\tau}=\delta_{R S P}=\delta_{R \tau}=0$ & 194.021 & $60.046 *$ & Reject $H_{0}$ \\
\hline$H_{0}: \gamma=\delta_{0}=\delta_{S P}=\delta_{\tau}=0$ & 196.602 & $54.884 *$ & Reject $H_{0}$ \\
\hline$H_{0}: \delta_{R \tau}=0$ & 223.748 & 0.592 & Accept $H_{0}$ \\
\hline$H_{0}: \delta_{R \tau}=\beta_{M S y}=\beta_{M S k}=\beta_{y y}=\beta_{L M S}=\beta_{y S P}=0$ & 220.173 & 7.742 & Accept $H_{0}$ \\
\hline \multicolumn{4}{|c|}{ Restriction : $\delta_{R \tau}=\beta_{M S y}=\beta_{M S k}=\beta_{y y}=\beta_{L M S}=\beta_{y S P}=0$} \\
\hline$H_{0}: \gamma=\delta_{0}=\delta_{R}=\delta_{S P}=\delta_{\tau}=\delta_{R S P}=0$ & 183.606 & $73.134 *$ & Reject $H_{0}$ \\
\hline$H_{0}: \gamma=\delta_{0}=\delta_{S P}=\delta_{\tau}=0$ & 187.523 & $65.300 *$ & Reject $H_{0}$ \\
\hline$H_{0}: \delta_{0}=\delta_{R}=\delta_{S P}=\delta_{\tau}=\delta_{R S P}=0$ & 198.855 & 42.636 & Reject $H_{0}$ \\
\hline$H_{0}: \delta_{R}=\delta_{S P}=\delta_{\tau}=\delta_{R S P}=0$ & 211.998 & 16.350 & Reject $H_{0}$ \\
\hline$H_{0}: \delta_{0}=0$ & 213.081 & 14.184 & Reject $H_{0}$ \\
\hline
\end{tabular}

* In this case the LR test statistic is asymptotically distributed as a mixture of chi-square distributions with degrees of freedom equal to the number of parameters assumed to be equal to zero in the null hypothesis $H_{0}$, provided $H_{0}$ is true. The critical values for this mixed $\chi^{2}$-distribution are obtained from Table 1 in Kodde and Palm (1986).

The hypotheses that the cost inefficiency effects are absent or that they have simpler distributions, together with the zero-restrictions on the $\beta$ and $\delta$ parameters implied by the discussion above, have been statistically tested using the generalized likelihood-ratio (LR) test. The LR test statistics reported in Table 2 are calculated as

$$
\Lambda=-2\left\{\ln \left[l\left(H_{0}\right) / l\left(H_{1}\right)\right]\right\}=-2\left\{\ln \left[l\left(H_{0}\right)\right]-\ln \left[l\left(H_{1}\right)\right]\right\},
$$

where $l\left(H_{0}\right)$ and $l\left(H_{1}\right)$ are the values of the likelihood function under the null and alternative hypotheses, $H_{0}$ and $H_{1}$, respectively. If $H_{0}$ is true, this test statistic is usually assumed to be asymptotically distributed as a chi-square $\left(\chi^{2}\right)$ random variable with degrees of freedom equal to the number of restrictions involved. However, difficulties arise in testing hypotheses where $\gamma$ is equal to 0 because $\gamma=0$ lies on the boundary of the parameter space for $\gamma$, given that it cannot take negative values. In all these cases, if $H_{0}$ is true, the generalized LR statistic, $\Lambda$, has 
asymptotic distribution which is a mixture of chi-square distributions whose critical values are obtained from Table 1 in Kodde and Palm (1986). ${ }^{40}$

It can be seen from Table 2 that the null hypothesis of absence of $\mathrm{X}$-inefficiency effects from the model (i.e., $H_{0}: \gamma=\delta_{0}=\delta_{R}=\delta_{S P}=\delta_{\tau}=\delta_{R S P}=\delta_{R \tau}=0$ ) is strongly rejected at 1 per cent level of significance. The second null hypothesis we consider, $H_{0}: \gamma=\delta_{0}=\delta_{S P}=\delta_{\tau}=0$, specifies that the inefficiency effects are not stochastic. If the parameter $\gamma$ is zero, then the variance of the $u_{f t} s$ is zero and so the model reduces to a traditional mean response function in which the $z$-variables, $R_{f t},\left(R_{f t} \times \ln S P_{f t}\right)$ and $\left(R_{f t} \times \tau_{f t}\right)$, are included in the cost function. ${ }^{41}$ Once again, the $H_{0}$ hypothesis is rejected at the 1 percent level of significance. Given the small estimate for the parameter $\delta_{R \tau}$ relative to its standard error underlined above, the third null hypothesis in Table 2 concerns the absence of significant effects on the cost inefficiency due to the interaction between time and regulation, $\left(R_{f t} \times \tau_{f t}\right)$. As expected, $H_{0}: \delta_{R \tau}=0$, i.e., the hypothesis that the marginal variation of the inefficiency term with respect to time, $\partial u_{f t} / \partial \tau_{f t}$, does not depend on the reimbursement rule faced by the company (or, alternatively, the differential impact of fixed-price schemes, $\partial u_{f t} / \partial R_{f t}$, is substantially the same across the years), is accepted. Re-estimating the model without $\delta_{R \tau}$, the estimates of the other parameters, $\beta$ and $\delta$, were little different from those obtained for the more general model, but the coefficients associated with the interaction of $P_{M S}$ with $Y, K$ and $P_{L}$, the interaction between $Y$ and $S P$, and the quadratic term for $Y$ persisted to be small and less than their estimated standard errors. Indeed, the LR statistic reported in Table 2 for testing the joint hypothesis $H_{0}: \delta_{R \tau}=\beta_{M S y}=\beta_{M S k}=\beta_{y y}=\beta_{L M S}=\beta_{y S P}=0$ is not significant and so we consider that the preferred stochastic frontier model has the seven parameters, $\delta_{R \tau}, \beta_{M S y}, \beta_{M S k}, \beta_{y y}, \beta_{L M S}$ and $\beta_{y S P}$, constrained to be equal to zero.

The estimates for the parameters of the restricted model are presented in the third column of Tables 1a and $1 \mathrm{~b}$. All the $\beta$ and $\delta$ coefficients for this model are larger than their estimated standard errors and most of them are statistically significant at the 1 percent level. ${ }^{42}$ Table 2 reports the LR statistics for testing the null hypotheses of absence of inefficiency effects (sixth row) and of absence of stochastic effects (seventh row). Both values are not significant. Similarly, the null hypotheses that the $u_{f t} s$ are altogether unrelated to the $z$-variables (eighth row), that they are not a linear function of the subsidization mechanisms, the network commercial speed, the year of observation and the interaction between regulation and speed (ninth row), and that they do not include an intercept parameter (tenth row), are all also rejected at the $1 \%$ level of significance. On the whole, these results show that the present data support the presence of stochastic X-inefficiency effects. Furthermore, the model specified for the inefficiency effects, involving a constant term, regulatory schemes, network speed, year of

\footnotetext{
${ }^{40}$ For more on the use of this test in stochastic frontier models, see Coelli (1995) and Coelli and Battese (1996).

${ }^{41}$ Note that the parameters $\delta_{0}, \delta_{S P}$ and $\delta_{\tau}$ cannot be identified if there are no random inefficiency effects in the model $(\gamma=0)$, as the cost function already involves an intercept term, $\beta_{0}$, a first-order coefficient for the speed effect, $\beta_{S P}$, and a parameter associated with the year of observation, $\beta_{\tau}$.

${ }^{42}$ Only the coefficient associated with the quasi-fixed input, $\beta_{k}$, is not statistically significant at the $10 \%$ level, while the parameters $\beta_{M S M S}$, in the frontier cost function, and $\delta_{0}$ and $\delta_{R S P}$, in the inefficiency model, are significant at the $10 \%$ and $5 \%$ level, respectively.
} 
observation and interaction between speed and regulation type, appears to be a significant component in our stochastic cost frontier analysis of the Italian LPT industry.

In the following section (5.1) we will take a brief look at the estimates of frontier cost elasticities and the technological properties for the preferred translog model. We postpone to Section 5.2 the discussion concerning detected $\mathrm{x}$-inefficiencies and the effects of regulatory schemes, which are our primary interest in this study.

\subsection{Technical characteristics}

Since all the variables (excepting time) in the cost function have been normalized to their sample mean value, and the variable cost as well as the regressors are in natural logarithm, the estimated first-order coefficients in the third column of Table la can be interpreted as frontier cost elasticities for the average operator of the industry. ${ }^{43}$ The focus of the analysis, in particular, is on the elasticities with respect to output, $\beta_{y}$, capital stock, $\beta_{k}$, commercial speed, $\beta_{S P}$, type of service, $\beta_{I N T C}$ and $\beta_{M I X}$, and time, $\beta_{\tau}$. These have been utilized to infer the characteristics of technology (evaluated at the sample mean) presented in Table 3, where the separated effects on frontier costs attributable to short-run $(S R S)$ and long-run returns to scale $(L R S)$, commercial speed improvements, shift of firm's production from urban to intercity and mixed services, and Hicks-neutral technological change are highlighted.

Table 3. Technology characteristics evaluated at the mean of the data (average firm)*

\begin{tabular}{|c|c|c|c|c|c|}
\hline Returns & to scale & \multirow{2}{*}{$\begin{array}{c}\text { Network speed } \\
\text { elasticity } \\
{\left[\beta_{S P}\right]}\end{array}$} & \multicolumn{2}{|c|}{ Service elasticities } & \multirow{2}{*}{$\begin{array}{c}\text { Technical } \\
\text { change } \\
{[-\beta \tau]}\end{array}$} \\
\hline $\begin{array}{c}\text { Short-run } \\
{\left[1 / \beta_{y}\right]}\end{array}$ & $\begin{array}{l}\text { Long-run } \\
{\left[\left(1-\beta_{k}\right) / \beta_{y}\right]}\end{array}$ & & $\begin{array}{c}\text { Intercity } \\
{\left[\exp \left(\beta_{\text {INTC }}\right)-1\right]}\end{array}$ & $\begin{array}{c}\text { Mixed } \\
{\left[\exp \left(\beta_{\mathrm{MIX}}\right)-1\right]}\end{array}$ & \\
\hline 1.89 & 1.83 & -0.18 & -0.08 & -0.12 & 0.015 \\
\hline$(0.05)$ & $(0.03)$ & $(0.04)$ & $(0.03)$ & $(0.02)$ & $(0.004)$ \\
\hline
\end{tabular}

* Estimated asymptotic standard errors are given in parentheses.

The analysis reveals the presence of short-run and long-run scale economies. Indeed, asymptotic t-tests lead to the acceptance of both hypotheses that $S R S$ and $L R S$ are significantly greater than one. The estimated $S R S, 1.89$, show that, given the endowment of quasi-fixed input, a more than proportional (almost double) output growth could be achieved by a proportional increase in the use of all variable factors, allowing the operator to reduce its unitary cost of production. As far as $L R S$ are concerned, ${ }^{44}$ the estimate, 1.83 , implies a suboptimal scale with respect to the long-run equilibrium. On the whole, these results highlight

\footnotetext{
${ }^{43}$ The average operator (the point of normalization) corresponds to a hypothetical firm operating at an average level of production $(542,216$ millions of places*traveled-kms), using an average stock of quasi-fixed input (276 age-vehicles), and facing average variable input prices $\left(P_{L}=68.3\right.$ millions lire/worker; $P_{M S}=13.41$ lire/seat-km; $P_{F}=1,037$ lire/litre) and average commercial speed $(23.3 \mathrm{kms} / \mathrm{h})$ over the sample.

${ }^{44}$ We can evaluate the long-run returns to scale by applying the algorithm first suggested by Caves et al. (1981) and indicated in square brackets in Table 3.
} 
the existence of unused capacity and support the conjecture that local monopoly is the relevant organization in the industry, at least for medium-sized firms.

The estimated frontier cost elasticity with respect to the average speed of the network in Table $3\left(\beta_{S P}=-0.18\right)$ bears out our insights about the influence on the production process of the specific environmental conditions characterizing the area where the service is provided. Increasing speed of LPT vehicles by 10 percent brings about the reduction in the level of operating costs for the average firm by about 1.8 percent. This result underlines the importance of appropriate public policies concerning local traffic regulation.

Third column of Table 3 reports service-specific cost elasticities associated with the dummies for the intercity (DINTC) and mixed (DMIX) activity. ${ }^{45}$ Both estimates have a negative sign and are statistically significant at the $1 \%$ level. The first value, -0.08 , means that a company operating in the intercity sector would suffer lower costs than an urban firm, and this probably reflects a lesser difficulty in managing networks out of the inner city. Estimated cost elasticity for the mixed service, -0.12 , indicates a lower operating cost for mixed networks not only with respect to urban firms, but also compared with the intercity ones. ${ }^{46}$ This suggests the existence of possible cost benefits, associated with the combined provision of urban and intercity services, which could arise from the better saturation of some sharable inputs. $^{47}$

Finally, Table 3 presents the estimated rate of Hicks neutral technological change, i.e., the rate of cost diminution from 1993 to $1999\left(-\partial \ln V C_{f t} / \partial \tau_{f t}=-\beta_{\tau}\right){ }^{48}$ As expected, variable costs are negatively related to the time variable: other things remaining unchanged, the annual rate of cost reduction due to technical progress is about 1.5 percent. This decrease in costs over time presumably reflects, to some extent, the greater care of the road maintenance and the replacement of worn-out fleet and the introduction of more fuel-efficient models of vehicles, ${ }^{49}$ made possible by the generous grants-in-aid government programs.

\footnotetext{
${ }^{45}$ Service-specific cost elasticities represent the percentage effect on variable costs due to the shift of the firm's production from urban to intercity or mixed service. The computation follows Halvorsen and Palmquist (1980).

${ }^{46}$ The differential impact on variable costs due to the shift of the firm's production from intercity to mixed services can be calculated as $\left[\exp \left(\beta_{M I X}-\beta_{I N T C}\right)-1\right]$ and is equal to -0.04 (statistically significant at the $5 \%$ level).

${ }^{47}$ In particular, we consider the workforce (drivers and administrative staff) and, perhaps to a lesser extent, the rolling stock.

${ }^{48}$ See Caves et al. (1981).

${ }^{49}$ Between 1993 and 1996 the fuel efficiency (kilometer run per liter of fuel) of the LPT companies included in our sample increased on average from 2.5 to 2.8. Furthermore, the total expenditure for spares and repairs decreased on average by about 154,000 lire per vehicle between 1996 and 1999. This probably contributed to the cost reduction over time highlighted above.
} 
Table 4. Estimated cost inefficiency by firm and year

\begin{tabular}{|c|c|c|c|c|c|c|c|c|}
\hline \multirow{2}{*}{ LPT company } & \multicolumn{8}{|c|}{ Year } \\
\hline & 1993 & 1994 & 1995 & 1996 & 1997 & 1998 & 1999 & All Years \\
\hline All Firms & 1.114 & 1.128 & 1.131 & 1.128 & 1.125 & 1.129 & 1.133 & 1.128 \\
\hline Firm 1 & - & - & - & 1.302 & 1.341 & 1.381 & - & 1.341 \\
\hline Firm 2* & 1.047 & 1.087 & 1.098 & 1.058 & 1.097 & 1.088 & 1.122 & 1.085 \\
\hline Firm 3 * & - & - & - & 1.024 & 1.025 & 1.030 & - & 1.026 \\
\hline Firm $4^{* * *}$ & 1.028 & 1.031 & 1.031 & 1.032 & 1.057 & 1.068 & 1.041 & 1.041 \\
\hline Firm $5^{*}$ & 1.192 & 1.170 & 1.079 & 1.038 & 1.033 & 1.025 & 1.028 & 1.081 \\
\hline Firm $6 \bullet$ & 1.061 & 1.037 & 1.056 & 1.033 & 1.026 & 1.029 & 1.040 & 1.040 \\
\hline Firm 7 & 1.149 & 1.148 & 1.116 & 1.098 & 1.137 & 1.171 & 1.162 & 1.140 \\
\hline Firm 8 * & - & - & - & 1.056 & 1.072 & 1.099 & - & 1.075 \\
\hline Firm 9 & - & - & - & 1.213 & 1.208 & 1.133 & - & 1.185 \\
\hline Firm $10^{*}$ & 1.081 & 1.161 & 1.248 & 1.261 & 1.245 & 1.253 & 1.181 & 1.204 \\
\hline Firm 11 & 1.192 & 1.201 & 1.100 & 1.081 & 1.089 & 1.157 & 1.233 & 1.150 \\
\hline Firm 12 & 1.032 & 1.033 & 1.063 & 1.069 & 1.077 & 1.075 & 1.109 & 1.066 \\
\hline Firm 13 & - & - & - & 1.342 & 1.337 & 1.329 & - & 1.336 \\
\hline Firm $14^{*}$ & 1.044 & 1.046 & 1.045 & 1.058 & 1.064 & 1.075 & 1.072 & 1.058 \\
\hline Firm 15 & - & - & - & 1.046 & 1.034 & 1.043 & - & 1.041 \\
\hline Firm 16 & 1.043 & 1.100 & 1.167 & 1.314 & 1.171 & 1.453 & 1.752 & 1.286 \\
\hline Firm 17 & 1.103 & 1.076 & 1.056 & 1.049 & 1.056 & 1.020 & 1.014 & 1.053 \\
\hline Firm 18* & - & - & - & 1.042 & 1.047 & 1.042 & - & 1.043 \\
\hline Firm 19 & - & - & - & 1.272 & 1.362 & 1.332 & - & 1.322 \\
\hline Firm 20 *** & 1.158 & 1.161 & 1.122 & 1.086 & 1.082 & 1.063 & 1.038 & 1.101 \\
\hline Firm 21 & 1.173 & 1.181 & 1.065 & 1.089 & 1.111 & 1.121 & 1.113 & 1.122 \\
\hline Firm 22 * & - & - & - & 1.071 & 1.063 & 1.076 & - & 1.070 \\
\hline Firm 23 & 1.025 & 1.057 & 1.038 & 1.093 & 1.075 & 1.043 & 1.024 & 1.051 \\
\hline Firm 24 & 1.116 & 1.097 & 1.211 & 1.096 & 1.104 & 1.076 & 1.186 & 1.126 \\
\hline Firm 25 & 1.916 & 1.881 & 1.948 & 1.887 & 1.770 & 1.754 & 1.663 & 1.831 \\
\hline Firm 26 & - & - & - & 1.020 & 1.133 & 1.162 & - & 1.105 \\
\hline Firm $27^{*}$ & 1.046 & 1.049 & 1.054 & 1.027 & 1.030 & 1.034 & 1.034 & 1.039 \\
\hline Firm 28 * & 1.052 & 1.030 & 1.035 & 1.070 & 1.051 & 1.051 & 1.095 & 1.055 \\
\hline Firm 29 & - & - & - & 1.060 & 1.061 & 1.070 & - & 1.064 \\
\hline Firm $30^{* * *}$ & 1.159 & 1.173 & 1.188 & 1.215 & 1.175 & 1.178 & 1.127 & 1.174 \\
\hline Firm 31 & 1.127 & 1.179 & 1.138 & 1.112 & 1.083 & 1.080 & 1.052 & 1.110 \\
\hline Firm 32 & - & - & - & 1.046 & 1.070 & 1.149 & - & 1.089 \\
\hline Firm $33^{*}$ & 1.070 & 1.104 & 1.076 & 1.026 & 1.025 & 1.024 & 1.030 & 1.051 \\
\hline Firm $34^{* * *}$ & 1.066 & 1.102 & 1.093 & 1.187 & 1.171 & 1.176 & 1.209 & 1.144 \\
\hline Firm $35^{*}$ & 1.043 & 1.039 & 1.089 & 1.186 & 1.106 & 1.095 & 1.067 & 1.089 \\
\hline Firm $36^{* * *}$ & 1.050 & 1.076 & 1.043 & 1.074 & 1.078 & 1.080 & 1.061 & 1.066 \\
\hline Firm 37 & 1.164 & 1.259 & 1.372 & 1.098 & 1.320 & 1.062 & 1.081 & 1.194 \\
\hline Firm 38 & 1.159 & 1.206 & 1.202 & 1.161 & 1.153 & 1.169 & 1.174 & 1.175 \\
\hline Firm 39 & 1.056 & 1.047 & 1.053 & 1.075 & 1.071 & 1.084 & 1.105 & 1.070 \\
\hline Firm 40 & - & - & - & 1.189 & 1.019 & 1.069 & - & 1.092 \\
\hline Firm $41^{* *}$ & 1.041 & 1.044 & 1.064 & 1.069 & 1.055 & 1.052 & 1.052 & 1.054 \\
\hline Firm $42 *$ & 1.124 & 1.105 & 1.138 & 1.337 & 1.322 & 1.232 & 1.112 & 1.196 \\
\hline Firm 43 * & 1.056 & 1.049 & 1.050 & 1.031 & 1.029 & 1.021 & 1.028 & 1.038 \\
\hline Firm $44^{*}$ & 1.024 & 1.025 & 1.026 & 1.019 & 1.020 & 1.020 & 1.019 & 1.022 \\
\hline Firm 45 & - & - & - & 1.029 & 1.038 & 1.047 & - & 1.038 \\
\hline
\end{tabular}

Companies managed under a fixed-price contract starting from $1989(\bullet), 1996(\star), 1997(\star \star)$, and $1998(\star \star \star)$. 


\subsection{Cost inefficiency and effects of regulatory schemes}

From Table 1b, we note first that the ML estimate for $\gamma$ in the preferred model is 0.966 with asymptotic standard error of 0.015 . This result is consistent with the conclusion that the true $\gamma$-value is accepted to be greater than zero (in the LR tests above) and the traditional average response function is not an adequate representation of the data. However, although the vast majority of residual variation is due to the cost inefficiency effects, $u_{f t}$, we also see that the $\gamma$ estimate is significantly less than one, to indicate that our stochastic frontier model [3]-[5] may be significantly different from a deterministic frontier specification, in which there are no random errors, $v_{f t}$, in the cost function.

The predicted $\mathrm{x}$-inefficiencies for each of the 45 transit companies over the different years involved are presented in Table 4. These estimates refer to the expression defined by equation [7] and have been obtained using the predictor presented in equation [A.13] of the Appendix. The mean overall cost inefficiency, that is, the arithmetic average of the estimated individual cost inefficiency for the sample firms over all the observations involved, is found to be 1.128. This means that, on average, the cost of production exceeds the minimum level frontier by 12.8 percent because of X-inefficiency. The positive coefficient for $\tau_{f t}$ in Table $1 \mathrm{~b}$ $\left(\delta_{\tau}=0.059\right)$ suggests that the inefficiencies of the Italian LPT firms tended to increase throughout the seven-year period. The first row of Table 4, which reports the estimates for mean cost inefficiency by year, confirms the worsening of performance over time: on average, the level of X-inefficiency increased slightly, from 11.4 percent in 1993 to 13.3 in 1999, with an upward swing during 1993-1995 and 1998-1999 and a brief downward swing over the period 1996 to 1997. As mentioned in Section 3.2, the deterioration of cost efficiency during the first half of the nineties may be traced in the laxity induced by the several actions taken by the Government with the purpose of covering the old deficits of LPT companies through extraordinary funds. On the contrary, the temporary efficiency recovery during 1996-1997 could be linked to expectations of tighter financial constraints triggered by the promulgation of the reform Law n. 549 in 1995, whereas the new rise in X-inefficiency observed in the years 1998 and 1999 probably reflects a let-up in the managerial effort induced by the delay in implementing the reform.

Although there is a general increase in the X-inefficiency of the transit companies over time, Table 4 shows that the individual predicted values vary considerably among firms in each year and they also change up and down over time for a given company. This leads to an investigation into the role played by the other $z$-factors included in model [5] that, jointly with time, determine such a variability in the inefficiency levels.

Our primary concern, in this work, is with the differential impact of regulatory schemes on cost efficiency. ${ }^{50}$ From Table $1 \mathrm{~b}$, the negative sign of $\delta_{R}(-0.868)$, the parameter related to

\footnotetext{
${ }^{50}$ Regarding this point, it is important to point out that before the estimation of the stochastic cost frontier model
} 
the subsidization mechanisms as such, without their interaction with network characteristics, confirms our conjecture of lower X-inefficiency levels for the units run under fixed-price schemes. Indeed, when compared over time, the results of Table 4 indicate a tendency of predicted cost inefficiency to diminish for most of the companies facing a transition from cost-plus to fixed-price reimbursement mechanisms. The differential impact of regulation is clearly observable in many cases where the subsidization practice changed from 1996 onwards, such as Firm 5 (7.9 percent in 1995, 3.8 in 1996 and 3.3 percent in 1997) or Firm 43 (5.0 percent in 1995, 3.1 in 1996 and 2.9 percent in 1997). Similar evidence is found for the transit systems which shifted from a cost-plus to a fixed-price scheme the following year or three years later, which happened for Firm 41 (6.9 percent in 1996, 5.5 in 1997 and 5.2 percent in 1998), Firm 4 (6.8 percent in 1998, 4.1 percent in 1999), or Firm 30 (17.8 percent in $1998,12.7$ percent in 1999).

The magnitude of the efficiency recovery differs from case to case, and not all the firms which faced a regulatory change exhibit better performances after the transition. This is due to the fact that the inefficiency estimates reported in Table 4 represent the combined effect of the regulation dummy and two other explanatory variables (besides time), viz., the average commercial speed of vehicles, that is a proxy for network characteristics, and its interaction with the subsidization mechanisms. Table $1 \mathrm{~b}$ shows that an increase in the network speed tends to lower X-inefficiency $\left(\delta_{S P}=-0.543\right)$, as the transit company faces more favourable exogenous operating conditions, and this effect is stronger for the units subjected to fixedprice schemes $\left(\delta_{R S P}=-0.976\right)$, presumably because of the higher cost reducing effort exerted by managers under this type of regulation. As explained in Section 3.2, from the latter result it is also proper to infer that when the intrinsic inefficiency of a network is too high (here due to a very low commercial speed), the impact of regulatory constraints on the overall cost efficiency becomes modest and in extreme circumstances is no longer perceptible (Gagnepain and Ivaldi, 2002a). Thus the greater efficiency recovery for some of the companies that moved towards fixed-priced mechanisms (e.g., Firm 33, Firm 43) can be partially attributed to

[3]-[5], we proceeded with conventional regression estimations of the cost function [3] with the dummy variable $\delta_{R}$ included in the specification. The results from a standard OLS model revealed that the introduction of fixedprice contracts lowers operating costs by close to $3 \%$ on average compared to the traditional cost-plus regulation. In a second model we included firm-specific effects to control for some types of endogeneity in the contract variable $\delta_{R}$. As Dalen \& Gomez-Lobo (2001, p. 14) highlight, "assume that the fixed-price contracts were introduced by strongly willed regulators, or in regions where there was a political preference for the efficient provision of transport services. In this case, it would be reasonable to assume that prior to the introduction of the new contracts these regulators were also successful in regulating companies efficiently through the traditional types of contracts. Then the new contracts would have been introduced in counties where companies already exhibited lower than average costs. Another type of endogeneity would occur if those counties where companies were particularly inefficient introduced the new type of contracts. In both cases, the contract variable would be endogenous, biasing the estimation results". The estimates for this second model showed that, even controlling for firm-specific effects, the shift to a subsidization practice based on fixed-price schemes still has a significant effect (although smaller than in the OLS model), lowering costs by $1.8 \%$. With these results in mind we proceeded to estimate the stochastic cost frontier model [3]-[5], in order to obtain more precise information about the impact on X-efficiency of fixed-price regulation. 
better network characteristics, as reflected in the higher level of average commercial speed. On the other hand, the modest effects of the regulatory change detected for some units in the sample, or even deterioration in the performance showed by others (e.g., Firm 14, Firm 35), is possibly imputable to worsened operating conditions, i.e., lower network speed, in addition to the impact exerted by time and the exogenous shocks captured by the stochastic term $w_{f t}$ that can have unfavorable repercussions on cost efficiency.

Table 5. Ranking of firms by mean cost distortion over the frontier (time period 1996-1998)*

\begin{tabular}{|c|c|c|c|c|c|}
\hline LPT company & \multicolumn{2}{|c|}{ Cost distortion } & \multirow{2}{*}{$\begin{array}{l}\text { LPT company } \\
\text { Firm } 2\end{array}$} & \multicolumn{2}{|c|}{ Cost distortion } \\
\hline Firm 44 & 0.020 & $(0.001)$ & & 0.081 & $(0.020)$ \\
\hline Firm 33 & 0.025 & $(0.001)$ & Firm 32 & 0.089 & $(0.054)$ \\
\hline Firm 3 & 0.026 & $(0.003)$ & Firm 31 & 0.091 & $(0.018)$ \\
\hline Firm 6 & 0.029 & $(0.004)$ & Firm 24 & 0.092 & $(0.015)$ \\
\hline Firm 43 & 0.030 & $(0.001)$ & Firm 40 & 0.092 & $(0.087)$ \\
\hline Firm 27 & 0.032 & $(0.006)$ & Firm 26 & 0.105 & $(0.075)$ \\
\hline Firm 5 & 0.032 & $(0.006)$ & Firm 21 & 0.107 & $(0.017)$ \\
\hline Firm 45 & 0.038 & $(0.009)$ & Firm 11 & 0.109 & $(0.041)$ \\
\hline Firm 15 & 0.041 & $(0.006)$ & Firm 35 & 0.129 & $(0.058)$ \\
\hline Firm 17 & 0.041 & $(0.019)$ & Firm 7 & 0.135 & $(0.036)$ \\
\hline Firm 18 & 0.043 & $(0.003)$ & Firm 37 & 0.160 & $(0.140)$ \\
\hline Firm 4 & 0.052 & $(0.019)$ & Firm 38 & 0.161 & $(0.008)$ \\
\hline Firm 28 & 0.057 & $(0.011)$ & Firm 30 & 0.176 & $(0.040)$ \\
\hline Firm 41 & 0.059 & $(0.009)$ & Firm 34 & 0.178 & $(0.008)$ \\
\hline Firm 29 & 0.064 & $(0.005)$ & Firm 9 & 0.185 & $(0.045)$ \\
\hline Firm 14 & 0.066 & $(0.009)$ & Firm 10 & 0.253 & $(0.025)$ \\
\hline Firm 22 & 0.070 & $(0.007)$ & Firm 42 & 0.297 & $(0.057)$ \\
\hline Firm 23 & 0.070 & $(0.025)$ & Firm 16 & 0.313 & $(0.141)$ \\
\hline Firm 36 & 0.071 & $(0.009)$ & Firm 19 & 0.322 & $(0.046)$ \\
\hline Firm 20 & 0.074 & $(0.018)$ & Firm 13 & 0.336 & $(0.007)$ \\
\hline Firm 12 & 0.074 & $(0.004)$ & Firm 1 & 0.341 & $(0.039)$ \\
\hline Firm 8 & 0.075 & $(0.022)$ & Firm 25 & 0.804 & $(0.073)$ \\
\hline Firm 39 & 0.077 & $(0.007)$ & & & \\
\hline
\end{tabular}

* Standard deviations are given in parentheses.

So far we have focused on the differential impact of regulatory schemes over time, by comparing predicted inefficiencies for a given LPT company before and after the introduction of a fixed-price mechanism. To better highlight the separated effects on cost efficiency of the regulation and network characteristics, as well as the relevance of their mutual interaction, it may be convenient to fix attention on cross-sectional comparisons among firms. In fact, it is in this context that the most marked variability in both the subsidization rules and the levels of average commercial speed can be observed. In such a way, we are also able to exploit the 
inefficiency estimates concerning companies for which a time-serial match of the two types of regulation is not possible, because of the lack of information over the period leading up to the adoption of fixed-price schemes (e.g., Firm 3, Firm 8, Firm 18).

For this study, we concentrate on the individual predicted inefficiencies pertaining to years 1996, 1997 and 1998. We have chosen this sub-period since, excepting Firm 41, for which a fixed-price oriented scheme has only been in force since 1997, the other 43 companies of our sample are univocally characterized by a definite regulatory mechanism during this years. In order to leave aside time effects, we calculated a mean inefficiency level over the period for each operator and considered the X-inefficiency values as average realizations of a specific subsidization rule. This allows us to classify the LPT firms on the basis of their inefficiency levels and to interpret the ensuing ranking in terms of the different regulatory schemes and network characteristics faced by each company. The list is presented in Table 5. Instead of reporting $C \hat{I}_{f t}$ we computed the percentage increase in costs due to Xinefficiency from the expression $\left\{C \hat{I}_{f t}-1\right\}$, so the entries in Table 5 can be directly taken as mean cost distortions over the frontier between 1996 and 1998. They have been ranked from the best performance (Firm 44), characterized by observed operating costs that are, on average, only 2 percent above the frontier, to the worst performance (Firm 25), for which the cost distortion reaches more than 80 percent. An important result emerging from Table 5 is that 8 of the top 11 firms were subjected to fixed-price mechanisms, whereas 9 of the bottom 11 companies faced a cost-plus regulation. Once again, our findings tend to corroborate the theoretical argument about the efficacy of high powered incentive schemes in increasing efficiency.

To better understand the role played by network characteristics (i.e., average commercial speed) in the above ranking, we assigned the individual predicted inefficiencies to four speed classes, defined in terms of brackets of average kilometers to the hour: very low speed, $S P_{v l}$ $\in[13,17.3]$; low speed, $S P_{l} \in[17.4,23.2]$; high speed, $S P_{h} \in[23.3,31.4]$; very high speed, $S P_{v h} \in[31.5,45.5]$. We then identified the operators subjected to cost-plus regimes, 0 , from units run under fixed-price ones, 1. Finally, we crossed the two types of categories, speed class and subsidization mechanism, and for each of the resultant groups we computed a mean cost distortion over the frontier. These values are reported in Table 6 (shaded square), that also presents mean cost distortions by regulatory scheme and speed class regardless of their interaction (first row and first column, respectively), together with the percentage decrease in $\mathrm{X}$-efficiency attainable by shifting from cost-plus to fixed-price regimes (regulation effect) and/or by improving operating conditions of the network (speed effect). 
Table 6. Mean cost distortion over the frontier by regulatory scheme and average commercial speed class (time period 1996-1998)

\begin{tabular}{|c|c|c|c|c|c|}
\hline \multirow{2}{*}{\multicolumn{2}{|c|}{$\begin{array}{l}\text { Average commercial } \\
\text { speed class }\end{array}$}} & \multicolumn{4}{|c|}{ Subsidization mechanism } \\
\hline & & $\begin{array}{c}\text { All } \\
\text { Schemes }\end{array}$ & $\begin{array}{l}\text { Cost-plus } \\
\text { scheme } \\
{[0]}\end{array}$ & $\begin{array}{c}\text { Fixed-price } \\
\text { scheme } \\
{[1]}\end{array}$ & $\begin{array}{l}\text { Regulation effect : } \\
\qquad(1-0) / 0\end{array}$ \\
\hline \multicolumn{2}{|c|}{ All speed classes* } & 0,1272 & 0,1561 & 0,0782 & $-49,29 \%$ \\
\hline $\begin{array}{l}\text { Very low } \\
\text { speed }\end{array}$ & {$\left[S P_{v l}\right]$} & 0,1735 & 0,1967 & 0,1397 & $-28,98 \%$ \\
\hline $\begin{array}{l}\text { Low } \\
\text { speed }\end{array}$ & {$\left[S P_{l}\right]$} & 0,1364 & 0,1712 & 0,0882 & $-48,48 \%$ \\
\hline $\begin{array}{l}\text { High } \\
\text { speed }\end{array}$ & {$\left[S P_{h}\right]$} & 0,1023 & 0,1121 & 0,0474 & $-57,72 \%$ \\
\hline $\begin{array}{l}\text { Very high } \\
\text { speed }\end{array}$ & {$\left[S P_{v h}\right]$} & 0,0888 & 0,0943 & 0,0253 & $-73,17 \%$ \\
\hline \multicolumn{6}{|c|}{ Speed effect : } \\
\hline \multicolumn{2}{|c|}{$\left(S P_{l}-S P_{v l}\right) / S P_{v l}$} & $-21 \cdot 38 \%$ & $-12,96 \%$ & $-36,86 \%$ & \\
\hline \multicolumn{2}{|c|}{$\left(S P_{h}-S P_{l}\right) / S P_{l}$} & $-25.00 \%$ & $-34,52 \%$ & $-46,26 \%$ & \\
\hline \multicolumn{2}{|c|}{$\left(S P_{v h}-S P_{h}\right) / S P_{h}$} & $-13.20 \%$ & $-15.88 \%$ & $-46,62 \%$ & \\
\hline
\end{tabular}

* Commercial speed classes have been defined in terms of brackets of average kilometers to the hour: $S P_{v l} \in[13$, 17.3]; $S P_{I} \in[17.4,23.2] ; S P_{h} \in[23.3,31.4] ; S P_{v h} \in[31.5,45.5]$.

First of all, the entries in Table 6 clearly confirm that both network characteristics and regulatory constraints matter in determining X-efficiency of LPT firms: for a company facing medium levels of commercial speed, the introduction of high powered incentive schemes allows, on average, an efficiency recovery around 49\% (first row-last column); similarly, more favorable traffic conditions for the LPT vehicles imply lower cost inefficiencies, with reductions which range from about $13 \%$ up to $25 \%$ according to the starting level of network speed, $S P_{v l}, S P_{l}, S P_{h}$, or $S P_{v h}$ (first column-bottom three rows).

Secondly, a general tendency emerges as the regulation effect becomes stronger as we move towards higher speed classes; on the other hand, the average efficiency gain that can be realized by making mobility more flowing is always greater in case of fixed-price regimes, given the higher effort level exerted by managers in the allocation of productive resources. In particular, two opposite groups of operators (the ones that are shaded more heavily in the square of Table 6) should be highlighted: in the first one, which includes units characterized by very high levels of network speed, the favorable operating conditions combined with fixed-price regulations leads to a remarkable inefficiency decrease, on average around $73 \%$ (from 9.43 to 2.53 percent); in the second group, gathering very slow speed networks, since 
the exogenous technical efficiency is likely to be rather low, the more intensive effort activity provided by managers in case of fixed-price schemes has a moderate effect on the Xinefficiency $(-29 \%)$ and the global cost distortions over the frontier remain heavy, on average about 14 percent.

These results can help explain the ranking of companies presented in Table 5 above. It should be more clear why the top three positions are held by companies facing very high levels of commercial speed combined with incentive subsidization mechanisms, while at the bottom of the list one observes mainly firms under cost-plus regulation with slow network speed. At the same time, we are also able to account for both the presence of companies subjected to cost-plus subsidization among the top ten performances, due to the favorable characteristics of their network, and the positioning of operators constrained by fixed-price schemes among the worst ten positions, because of the very low levels of their commercial speed.

\section{Conclusion and policy implications}

On the whole, the results of this study indicate a significant impact of regulatory constraints on the cost efficiency of the Italian LPT companies. First, the theoretical prediction (Laffont and Tirole, 1993) that fixed-price schemes provide more incentives for efficiency is validated: given similar network characteristics, operators run under a fixed-price mechanism have a lower cost distortion than operators subjected to a cost-plus regulation. Moreover, to some extent the inefficiency differentials among companies can be due to differences in the commercial speed levels. The latter contribute to determining what Gagnepain \& Ivaldi (2002a) called the intrinsic inefficiency of a network and can seriously undermine the efficacy of incentive regulatory policies. In the light of the evidence found for the operators facing very low commercial speed levels, if the exogenous operating conditions are too unfavorable, then fixed-price subsidization mechanisms become less successful instruments for recovering efficiency.

Besides confirming the importance of incentive regulation theory for the cost structure analysis of regulated utilities, our findings also provide useful guidelines for the policy interventions concerning local mobility. Significant reductions of $\mathrm{X}$-inefficiency can be obtained by resorting to fixed-price subsidies, and the ongoing reform in Italy is correctly moving towards this direction. A proper definition of quality and cost standards is requested, so that the service contract between the regulatory authority and LPT operator gives the firm's manager the incentives to optimize the allocation of productive resources. Our results also stress the impact of network characteristics and underline the importance of local traffic regulation. In fact, a more flowing mobility for LPT vehicles would have positive effects on both technology (higher commercial speeds lower the minimum-cost frontier) and $\mathrm{X}$ - 
efficiency levels (higher commercial speeds move firm performances closer to the bestpractice behavior). This could be pursued, for instance, by acting on factors such as the reallocation of existing road space away from private vehicles towards public passenger transport (e.g., reserved lanes for trams and buses, restrictions on parking and traffic of cars and taxis), or the provision of incentives for the use of public modes (e.g., good intra- and inter-modal timetable coordination, introduction of multi-modal travelcards).

In conclusion, there is scope for transport policy to increase the cost efficiency of LPT companies. Efforts have to be intensified in the twofold direction of replacing cost-plus subsidization mechanisms with high-powered incentive schemes, as well as improving exogenous operating conditions of the network. Indeed, a peculiarity of our study is to highlight the complementarity between the effects exerted by these two instruments. Local authorities will have to define the proper mix of interventions according to the specific regulatory framework and environmental factors faced by single transit firms. 


\section{Appendix}

The log-likelihood function presented in the Appendix of the Battese and Coelli (1993) working paper refers to a stochastic frontier production function, with the $u_{f t} s$ interpreted as pure technical inefficiency effects, which cause the firm to operate below the production frontier. If we wish to specify a stochastic frontier cost function, we have to alter the global error term specification from $\psi_{f t}=\left(v_{f t}-u_{f t}\right)$, as in Battese and Coelli (1993), to $\psi_{f t}=\left(v_{f t}+u_{f t}\right)$, as in the equation [2] reported in the text. ${ }^{51}$ The $u_{f t} s$ now define how far the firm operates above the cost frontier and involve both technical and allocative inefficiencies. The loglikelihood function for the cost frontier specification analogue of the Battese and Coelli model can be obtained by making a few simple sign changes and is reproduced here.

For simplicity of presentation of results in this Appendix, we assume that the stochastic frontier cost model [1]-[2] is expressed by

$$
\begin{aligned}
& v c_{f t}=v c\left(x_{f t} ; \beta\right)+\psi_{f t} \\
& \psi_{f t}=v_{f t}+u_{f t} \\
& f=1, \ldots, F, \text { and } t=1, \ldots, T_{f},
\end{aligned}
$$

where $v c_{f t}=\ln V C_{f t}, v c()=.\ln V C($.$) and x_{f t}$ is a vector which groups the arguments of the variable cost function, $Y_{f t}, P_{f t}, Z_{f t}$, and $\tau_{f t}$; further, $v_{f t} \sim$ i.i.d. $N\left(0, \sigma_{v}{ }^{2}\right)$ and $u_{f t} \sim N^{+}\left(\delta^{\prime} z_{f t}, \sigma_{u}{ }^{2}\right)$.

The density functions for $v_{f t}$ and $u_{f t}$ are

$$
f_{V}(v)=\frac{\exp \left\{-\frac{1}{2} v^{2} / \sigma_{v}^{2}\right\}}{\sqrt{2 \pi} \sigma_{v}}, \quad-\infty<v<\infty
$$

and

$$
f_{U}(u)=\frac{\exp \left\{-\frac{1}{2}\left(u-\delta^{\prime} z\right)^{2} / \sigma_{u}^{2}\right\}}{\sqrt{2 \pi} \sigma_{u} \Phi\left[\delta^{\prime} z / \sigma_{u}\right]}, u \geq 0,
$$

where the subscripts, $f$ and $t$, are omitted for convenience in the presentation; and $\Phi[$.$] is the$ standard normal cumulative distribution function.

Given the independence assumption, the joint density function for $u$ and $v$ is the product of their individual density functions. Then, since $\psi=v+u$, the joint density function for $\psi$ and $u$ is

$$
f_{\Psi, U}(\psi, u)=\frac{\exp -\frac{1}{2}\left\{\left[\left(u-\delta^{\prime} z\right)^{2} / \sigma_{u}^{2}\right]+\left[(\psi-u)^{2} / \sigma_{v}^{2}\right]\right\}}{2 \pi \sigma_{u} \sigma_{v} \Phi\left[\delta^{\prime} z / \sigma_{u}\right]}, \quad u \geq 0
$$

\footnotetext{
${ }^{51}$ The inefficiency effect, $u_{f t}$, is added in the stochastic cost frontier instead of being subtracted, as in the case of the stochastic production frontier, because the cost function represents minimum cost, whereas the production function represents maximum output.
} 


$$
=\frac{\exp -\frac{1}{2}\left\{\left[\left(u-\mu_{*}\right)^{2} / \sigma_{*}^{2}\right]+\left[\left(\psi-\delta^{\prime} z\right)^{2} /\left(\sigma_{v}^{2}+\sigma_{u}^{2}\right)\right]\right\}}{2 \pi \sigma_{u} \sigma_{v} \Phi\left[\delta^{\prime} z / \sigma_{u}\right]},
$$

where

$$
\mu_{*}=\frac{\sigma_{v}^{2} \delta^{\prime} z+\sigma_{u}^{2} \psi}{\sigma_{v}^{2}+\sigma_{u}^{2}}
$$

and

$$
\sigma_{*}^{2}=\sigma_{v}^{2} \sigma_{u}^{2} /\left(\sigma_{v}^{2}+\sigma_{u}^{2}\right)
$$

Thus the marginal density function for $\psi=v+u$ is obtained by integrating $u$ out of $f_{\Psi, U}(\psi, u)$, which yields

$$
f_{\Psi}(\psi)=\frac{\exp -\frac{1}{2}\left\{\left(\psi-\delta^{\prime} z\right)^{2} /\left(\sigma_{v}^{2}+\sigma_{u}^{2}\right)\right\}}{\sqrt{2 \pi}\left(\sigma_{u}^{2}+\sigma_{v}^{2}\right)^{1 / 2}\left\{\Phi\left[\delta^{\prime} z / \sigma_{u}\right] / \Phi\left[\mu_{*} / \sigma_{*}\right]\right\}} .
$$

Using the expression in equation [A.8], the density function for the cost value, $v c_{f t}$, in equation [A.1] can be written as

$$
f_{V C_{f t}}\left(v c_{f t}\right)=\frac{\exp -\frac{1}{2}\left\{\frac{\left[v c_{f t}-v c\left(x_{f t} ; \beta\right)-\delta^{\prime} z\right]^{2}}{\sigma_{v}^{2}+\sigma_{u}^{2}}\right\}}{\sqrt{2 \pi}\left(\sigma_{u}^{2}+\sigma_{v}^{2}\right)^{1 / 2}\left\{\Phi\left[d_{f t}\right] / \Phi\left[d_{f t}^{*}\right]\right\}},
$$

where $d_{f t}=\delta^{\prime} z_{f t} / \sigma_{u}, d_{f t}^{*}=\mu_{f t}^{*} / \sigma_{*}$ and $\mu_{f t}^{*}=\left[\sigma_{v}^{2} \delta^{\prime} z_{f t}+\sigma_{u}^{2}\left(v c_{f t}-v c\left(x_{f t} ; \beta\right)\right] /\left(\sigma_{u}^{2}+\sigma_{v}^{2}\right)\right.$.

Given that there are $T_{f}$ observations obtained for the $f^{\text {th }}$ firm, where $1 \leq T_{f} \leq T$, and $v c_{f}$ $\equiv\left(v c_{f 1}, v c_{f 2}, \ldots, v c_{f T_{f}}\right)$ denotes the vector of the $T_{f}$ cost values in equation [A.1], then the logarithm of the likelihood function for the sample observations, $v c \equiv\left(v c_{1}{ }^{\prime}, v c_{2}^{\prime}, \ldots, v c_{F}^{\prime}\right)^{\prime}$, is

$$
\begin{aligned}
L(\Theta ; v c)= & -\frac{1}{2}\left(\sum_{f=1}^{F} T_{f}\right)\left\{\ln 2 \pi+\ln \sigma^{2}\right\} \\
& -\frac{1}{2} \sum_{f=1}^{F} \sum_{t=1}^{T_{f}}\left\{\left[v c_{f t}-v c\left(x_{f t} ; \beta\right)-\delta^{\prime} z_{f t}\right]^{2} / \sigma^{2}\right\} \\
& -\sum_{f=1}^{F} \sum_{t=1}^{T_{f}}\left\{\ln \Phi\left[d_{f t}\right]-\ln \Phi\left[d_{f t}^{*}\right]\right\},
\end{aligned}
$$

where the re-parameterization suggested by Battese and Corra (1977) is used: $\sigma^{2} \equiv\left(\sigma_{v}{ }^{2}+\sigma_{u}{ }^{2}\right)$ and $0 \leq \gamma \equiv \sigma_{u}{ }^{2} /\left(\sigma_{v}{ }^{2}+\sigma_{u}{ }^{2}\right) \leq 1$. Moreover, $\Theta \equiv\left(\beta^{\prime}, \delta^{\prime}, \sigma^{2}, \gamma\right)^{\prime}, d_{f t}=\delta^{\prime} z_{f t} /\left(\gamma \sigma^{2}\right)^{1 / 2}$, $d_{f t}^{*}=\mu_{f t}^{*} /\left[\gamma(1-\gamma) \sigma^{2}\right]^{1 / 2}, \mu_{f t}^{*}=(1-\gamma) \delta^{\prime} z_{f t}+\gamma\left(v c_{f t}-v c\left(x_{f t} ; \beta\right)\right)$, and $\sigma_{*}=\left[\gamma(1-\gamma) \sigma^{2}\right]^{1 / 2}$.

The log-likelihood function in equation [A.10] can be maximized with respect to each element of $\Theta$ to obtain maximum likelihood (ML) estimates of all parameters, $\beta, \delta, \sigma^{2}$ and $\gamma$. 
Predictions of the cost inefficiency for each producer, $f$, at each observation, $t$, have then to be derived. Since we have estimates of $\psi_{f t}=v_{f t}+u_{f t}$, according to the original insight of Jondrow et al. (1982), a solution to the problem is obtained from the conditional distribution of $u_{f t}$ given $\psi_{f t}$. The latter incorporates whatever information $\psi_{f t}$ contains about the unobservable component $u_{f t}$. Using equations [A.5] and [A.8], the conditional density function of $u_{f t}$ given $\Psi_{f t}=\psi_{f t}$ is given $b^{52}$

$$
f_{U \mid \Psi=\psi}(u)=\frac{\exp -\frac{1}{2}\left\{\left(u-\mu_{*}\right)^{2} / \sigma_{*}^{2}\right\}}{\sqrt{2 \pi} \sigma_{*} \Phi\left[\mu_{*} / \sigma_{*}\right]} .
$$

The overall cost efficiency of the $f^{\text {th }}$ firm at the $t^{\text {th }}$ observation, $C E_{f t}$, may be expressed as the ratio of stochastic frontier minimum cost (with $u_{f t}=0$ ) to observed cost, which is equal to $^{53}$

$$
C E_{f t}=\frac{1}{\exp \left\{u_{f t}\right\}}=\exp \left\{-u_{f t}\right\}
$$

This measure is bounded between zero $\left(u_{f t} \rightarrow \infty\right)$ and one $\left(u_{f t}=0\right)$. Its prediction can be obtained by minor sign alterations of the technical efficiency point estimator presented in Battese and Coelli (1993), which is a generalization of the results by Jondrow et al. (1982) and Battese and Coelli (1988). It is derived using the conditional density function of $u_{f t}$ given $\Psi_{f t}=\psi_{f t}$ specified in equation [A.11] and is given by

$$
C \hat{E}_{f t}=E\left(\exp \left\{-u_{f t}\right\} \mid \Psi_{f t}=\psi_{f t}\right)=\left\{\frac{\Phi\left[\left(\mu_{f t}^{*} / \sigma_{*}\right)-\sigma_{*}\right]}{\Phi\left[\mu_{f t}^{*} / \sigma_{*}\right]}\right\} \exp \left\{-\mu_{f t}^{*}+\frac{1}{2} \sigma_{*}^{2}\right\},
$$

where $E($.$) denotes the conditional expectation of C E_{f t}$ upon the observed value of $\psi_{f t}$, while $\mu_{f t}^{*}$ and $\sigma_{*}$ have been defined above.

Starting from the estimated stochastic cost frontier, the «FRONTIER Version 4.1» computer program returns an estimate of cost inefficiency for each producer at each observation, i.e. a prediction of $C I_{f t}=\exp \left\{u_{f t}\right\}$. It measures the extent to which observed costs exceed the corresponding stochastic frontier values. It is then calculated as the inverse of $C E_{f t}$ in equation [A.12], the latter being predicted by applying the point estimator specified in equation [A.13].

\footnotetext{
${ }^{52}$ Again the subscripts, $f$ and $t$, are omitted in the following expressions for convenience in the presentation.

${ }^{53}$ Expression [A.12] is appropriate for $C E_{f t}$ only if the general specification of the stochastic frontier cost model is given by equations [1]-[2] in the text.
} 


\section{References}

Afriat, S. N., "Efficiency Estimation of Production Functions", International Economic Review, 13(3), October 1972, pp. 568-598.

Aigner, D. J. and Chu, S. F., "On Estimating the Industry Production Function", American Economic Review, 58(4), September 1968, pp. 826-839.

Aigner, D., Lovell, K. C. A. and Schmidt, P. G., "Formulation and Estimation of Stochastic Frontier Production Function Models", Journal of Econometrics, 6, 1977, pp. 21-37.

Battese, G. E. and Coelli, T. J., “A Model for Technical Inefficiency Effects in a Stochastic Frontier Production Function for Panel Data”, Empirical Economics, 20, 1995, pp. 325332.

Battese, G. E. and Coelli, T. J., "A Stochastic Frontier Production Function Incorporating a Model for Technical Inefficiency Effects", Working Paper in Econometrics and Applied Statistics, 69, Department of Econometrics, University of New England, Armidale, 1993.

Battese, G. E. and Coelli, T. J., "Prediction of Firm-Level Technical Efficiencies: With a Generalized Frontier Production Function and Panel Data", Journal of Econometrics, 38, 1988, pp. 387-399.

Battese, G. E. and Corra, G. S., "Estimation of a Production Frontier Model: With Application to the Pastoral Zone of Eastern Australia", Australian Journal of Agricultural Economics, 21, 1977, pp. 169-179.

Caves, D. W., Christensen, L. R., and Swanson, J. A., "Productivity Growth, Scale Economies and Capacity Utilization in U. S. Railroads", American Economic Review, 1981, 71, pp. 994-1002.

Caves, D. W., Christensen, L. R., Tretheway, M. W. and Windle, R., "Network Effects and the Measurement of Returns to Scale and Density for U.S. Railroads", in Daughety, A., Analytical Studies in Transport Economics, Cambridge, Cambridge University Press, 1985, pp. 97-120.

Coelli, T. J. and Battese, G. E., "Identification of Factors which Influence the Technical Efficiency of Indian Farmers", Australian Journal of Agricultural Economics", 40(2), 1996, pp. 19-44.

Coelli, T. J., "A Guide to FRONTIER Version 4.1: A Computer Program for Stochastic Frontier Production and Cost Function Estimation", CEPA Working Paper, 7, Centre for Efficiency and Productivity Analysis, University of New England, Armidale, 1996.

Coelli, T. J., "Estimators and Hypothesis Tests for a Stochastic Frontier Function: A Monte Carlo Analysis", Journal of Productivity Analysis, 6, 1995, pp. 247-268.

Cornes, R., Duality and Modern Economics, Cambridge, Cambridge University Press, 1992.

Dalen, D. M. and Gomez-Lobo, A., "Cost Functions in Regulated Industries Characterized by Asymmetric Information", European Economic Review, 41(3-5), April 1997, pp. 93542.

Dalen, D. M. and Gomez-Lobo, A., Regulation and Incentive Contracts: An Empirical Investigation of the Norwegian Bus Transport Industry, Institute for Fiscal Studies Working Paper, London, 1996.

Dalen, D. M. and Gomez-Lobo, A., Yardsticks on the Road: Regulatory Contracts in the Norwegian Bus Industry, Department of Economics Working Paper, University of Chile, 2001. 
Fabbri, D., "La Stima di Frontiere di Costo nel Trasporto Pubblico Locale: una Rassegna and un'Applicazione", Economia Pubblica, 3, 1998, pp. 55-94.

Filippini M., "Economies of Scale and Utilization in the Swiss Electric Power Distribution Industry", Applied Economics, 28, 1996, pp. 543-550.

Gagnepain, P. and Ivaldi, M., "Incentive Regulatory Policies: The Case of Public Transit Systems in France", GREMAQ-IDEI Working Paper, Université des Sciences Sociales de Toulouse, forthcoming in RAND Journal of Economics, 2002b.

Gagnepain, P. e Ivaldi, M., "Stochastic Frontiers and Asymmetric Information Models", Journal of Productivity Analysis, 18(2), 2002a, pp. 145-159.

Gagnepain, P., "Structures Productives de l'Industrie du Transport Urbain et Effets des Schemas Reglementaires", Economie et Prevision, 135, July-Sept. 1998, pp. 95-107.

Halvorsen, R. and Palmquist, R., "The Interpretation of Dummy Variable in Semilogarithmic Equations", American Economic Review, 70(3), 1980, pp. 474-475.

Huang, C. J. and Liu, J. T., "Estimation of a Non-Neutral Stochastic Frontier Production Function”, Journal of Productivity Analysis, 5, 1994, pp. 171-180.

Jondrow, J., Lovell, K. C. A., Materov, I. and Schmidt, P., "On the Estimation of Technical Efficiency in the Stochastic Production Function Model, Journal of Econometrics, 19, 1982, pp. 233-238.

Kalirajan, K. P. and Shand, R. T., "Estimating Location-specific and Firm-specific Technical Efficiency: An Analysis of Malaysian Agricultural", Journal of Economic Development, 11, 1989, pp. 147-160.

Kalirajan, K. P., "An Econometric Analysis of Yield variability in Paddy Production", Canadian Journal of Agricultural Economics, 29, 1981, pp. 283-294.

Kerstens, K., "Technical Efficiency Measurement and Explanation of French Urban Transit Companies", Transportation Research, Vol. 30(6), 1996, pp. 431-452.

Kumbhakar, S. C. and Lovell, C. A. K., Stochastic Frontier Analysis, Cambridge University Press, Cambridge, 2000.

Kumbhakar, S. C., Ghosh, S. and McGuckin, J. T., "A Generalized Production Frontier Approach for Estimating Determinants o Inefficiency in US Dairy Farms", Journal of Business and Economic Statistics, 9(3), July, 1991, pp. 279-286.

Laffont, J. J. and Tirole, J., A Theory of Incentives in Procurement and Regulation, MIT Press, Cambridge, 1993.

Leibenstein, H., “Allocative Efficiency versus «X-Efficiency»”, American Economic Review, 56, 1966, pp. 392-415.

Levaggi, R., "Parametric and Non-Parametric Approach to Efficiency: The Case of Urban Transport in Italy", Studi Economici, 49(53), 1994, pp. 67-88.

Mensah, Y. M., "A Simplification of the Kopp-Diewert Method of Decomposing Cost Efficiency and Some Implications", Journal of Econometrics, 60, 1994, pp. 133-144.

Mester, L. J., "Measuring Efficiency at US Banks: Accounting for Heterogeneity Is Important", European Journal of Operational Research, 98(2), April, 1997, pp. 230242.

Ministry of Transports and Navigation, I trasporti in Italia, Istituto Poligrafico e Zecca dello Stato, Italy, Rome, 1997.

Pitt, M. M. and Lee, M. F., "The Measurement and Sources of Technical Inefficiency in the Indonesian Weaving Industry", Journal of Development Economics, 9, 1981, pp. 43-64. 
Reifschneider, D. and Stevenson, R., "Systematic Departures from the Frontier: A Framework for the Analysis of Firm Inefficiency", International Economic Review, 32, 1991, pp. 715-723.

Schmidt, P., "On the Statistical Estimation of Parametric Frontier Production Functions", Review of Economics and Statistics, 58(2), May 1976, pp. 238-239.

Windle, R. J., "Transit Policy and the Cost Structure of Urban Bus Transportation", in J. S. Dogson and N. Topham eds., Bus Deregulation and Privatization, Averbury: Aldershot, 1988.

Wunsch, P., Estimating Menus of Linear Contracts for Mass Transit Firms, Université Catholique de Louvain-CORE Discussion Paper: 96/40, September 1996. 